\title{
Honeywell
}

\section{Lightning Arrestor Connectors Production Readiness}

Federal Manufacturing \& Technologies

Steve Marten

Jim Emmons

Dawud Hasam
Kim Linder

Antonio Gomez

Michelle Maurer

\section{KCP-613-8510}

Published October 2008

Final Report on 706500, 703010, 703044

Approved for public release; distribution is unlimited.

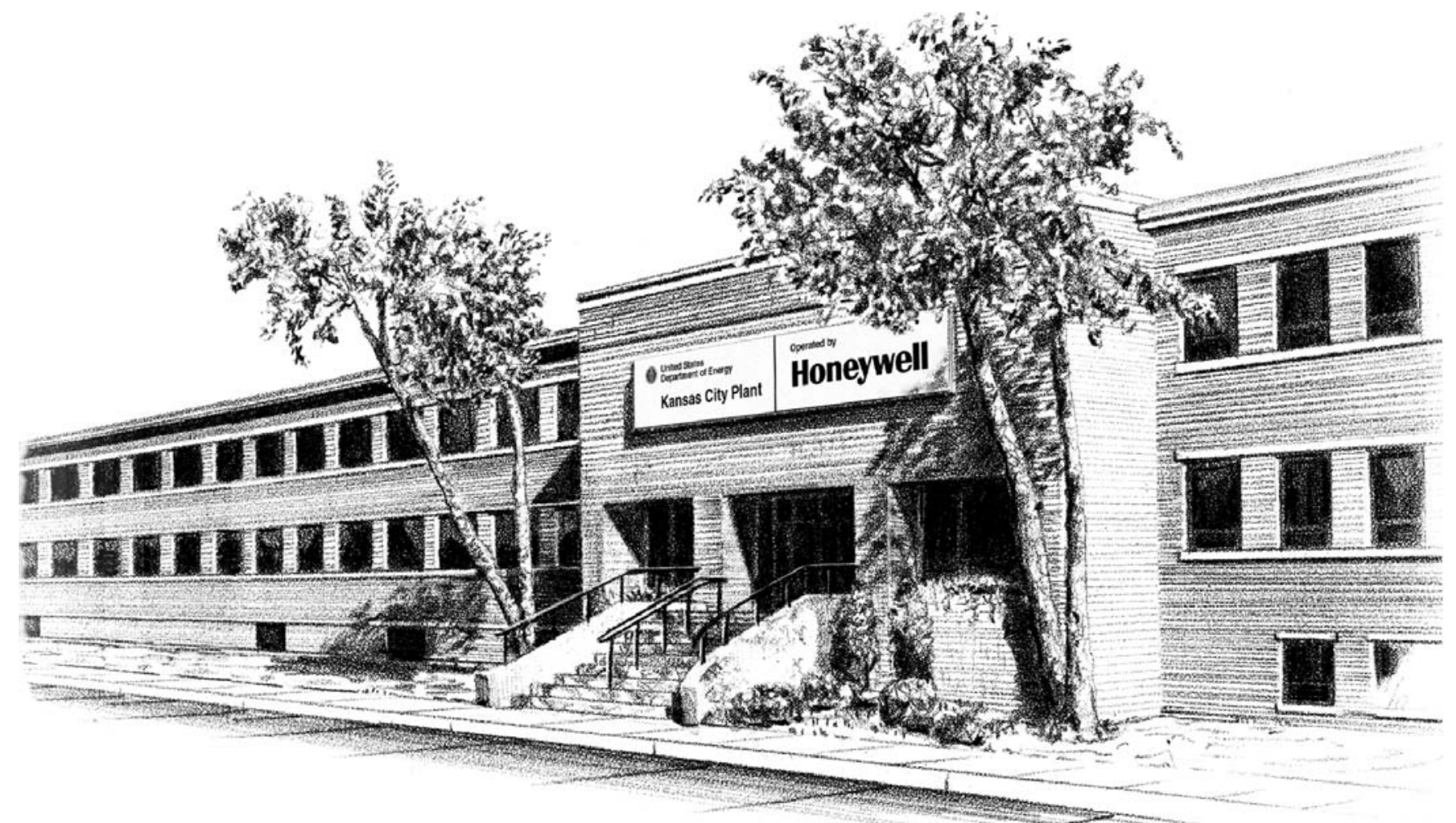

Prepared under prime contract DE-ACO4-01AL66850 for the 


\section{DISCLAIMER}

This report was prepared as an account of work sponsored by an agency of the United States Government. Neither the United States Government nor any agency thereof, nor any of their employees, makes any warranty, express or implied, or assumes any legal liability or responsibility for the accuracy, completeness, or usefulness of any information, apparatus, product, or process disclosed, or represents that its use would not infringe privately owned rights. Reference herein to any specific commercial product, process or service by trade names, trademark, manufacturer, or otherwise, does not necessarily constitute or imply its endorsement, recommendation or favoring by the United States Government or any agency thereof. The views and opinions of authors expressed herein do not necessarily state or reflect those of the United States Government or any agency thereof.

All data prepared, analyzed and presented has been developed in a specific context of work and was prepared for internal evaluation and use pursuant to that work authorized under the reference contract. Reference herein to any specific commercial product, process or service by trade name, trademark, manufacturer, or otherwise, does not necessarily constitute or imply its endorsement, recommendation or favoring by the United States Government, any agency thereof or Honeywell Federal Manufacturing \& Technologies, LLC.

Printed in the United States of America.

This report has been reproduced from the best available copy.

Available to DOE and DOE contractors from the Office of Scientific and Technical Information, P.O. Box 62, Oak Ridge, Tennessee 37831; prices available from (865) 576-8401, FTS 626-8401.

Available to the public from the National Technical Information Service, U.S. Department of Commerce, 5285 Port Royal, Rd., Springfield, Virginia 22161, (703) 487-4650.

A prime contractor with the United States Department of Energy under prime contract DE-ACO4-01AL66850.
Honeywell Federal Manufacturing \& Technologies P. O. Box 419159

Kansas City, Missouri, 64141-6159 


\section{Honeywell}

KCP-613-8510

Distribution Category UC-42

Approved for public release; distribution is unlimited.

\section{LIGHTNING ARRESTOR CONNECTOR PRODUCTION READINESS}

Steve Marten

Jim Emmons

John Hilton

Dawud Hasam

Kim Linder

Antonio Gomez

Michelle Maurer

Published October 2008

Final Report on 703010, 706500, 703044

Project Team:

Steve Marten

Jim Emmons

John Hilton

Dawud Hasam

Angela Kartsonis

Ernie Belarde

Dan Cogan

Chris Campbell

Kim Linder

Antonio Gomez

Michelle Maurer

Wayne Tuohig

Dennis Eichorst 


\section{Contents}

Section

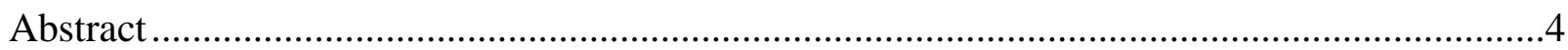

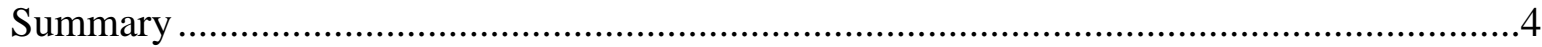

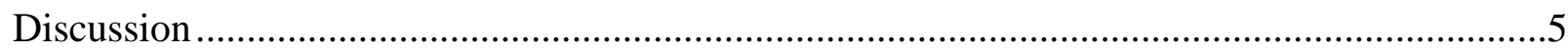

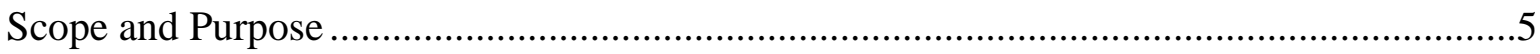

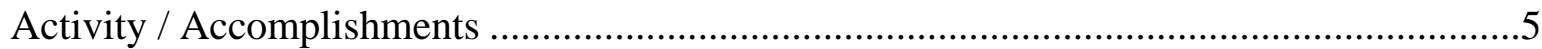

706500 Hermetic Connector Sealing Improvement ...............................................5

703044, 703010 LAC Production Readiness..........................................................18

706500 LAC Granule Knowledge Preservation .......................................................23

706500 LAC Shell Second Vendor Activities ........................................................24

706500 LAC Pin Placement Verification System .................................................25

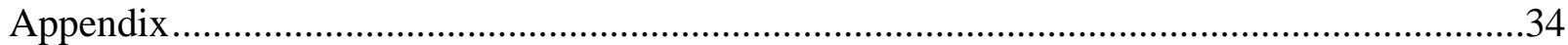




\section{Figures}

Figure

Figure 1: Connector Shell Assembly D-Flat................................................................. 6

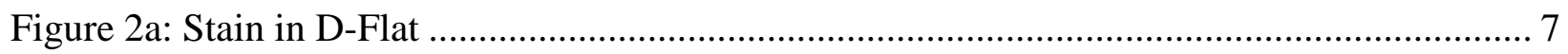

Figure 2b: Stain (Leak Path) Highlighted By Dye Penetrant ................................................ 7

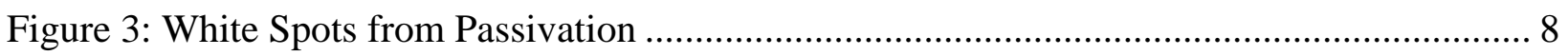

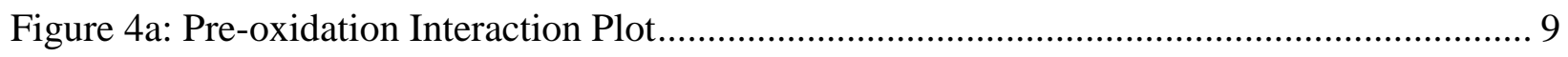

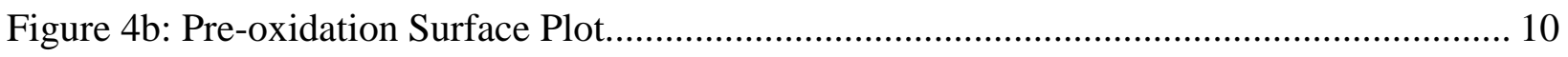

Figure 5a: Day 1 Pre-oxidation Analysis Of Variance ..................................................... 11

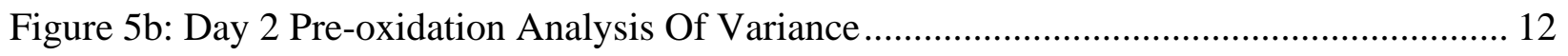

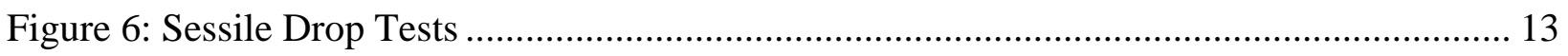

Figure 7: Oxide Thickness for LAC DOE \#3 (Pre-oxidation Experiment)

Data from oxide measurements performed at Sandia............................................ 14

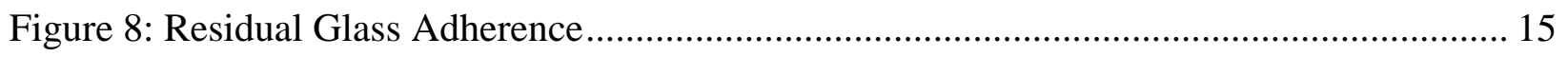

Figure 9: Pareto Chart of the Standardized Effects .............................................................. 15

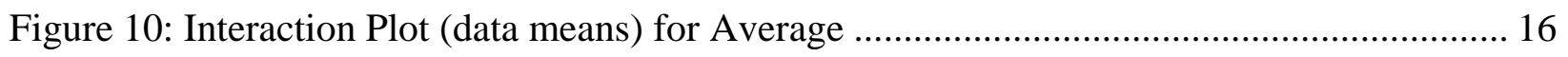

Figure 11: Main Effects Plot (data means) for Oxidation Average ......................................... 17

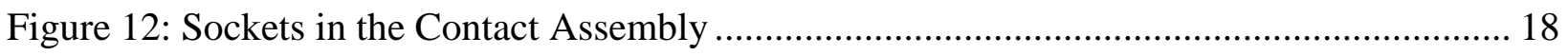

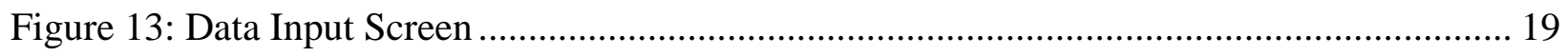

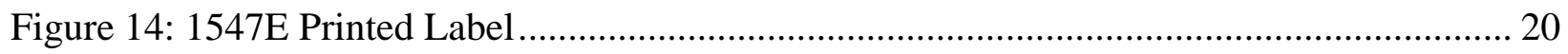

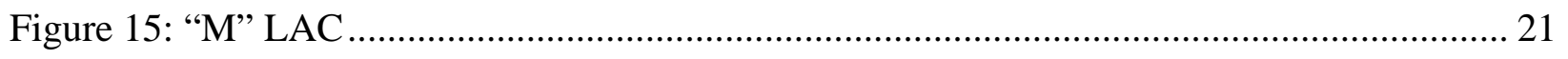

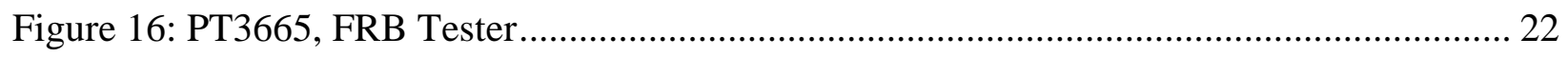


Figure 17: Screen shot from Knowledge Preservation Web Site

Figure 18: Screen shot from Knowledge Preservation Web Site ............................................ 23

Figure 19: LAC Pin Placement Verification System.......................................................... 27

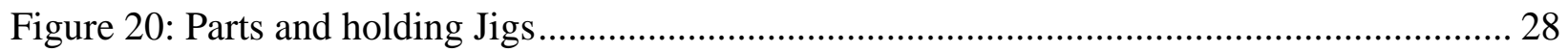

Figure 21: System simplified block diagram ............................................................... 28

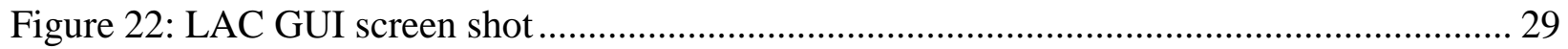

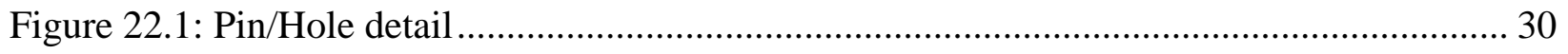

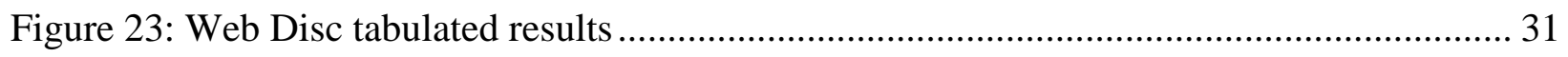

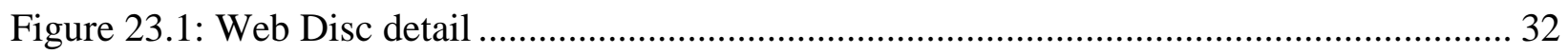

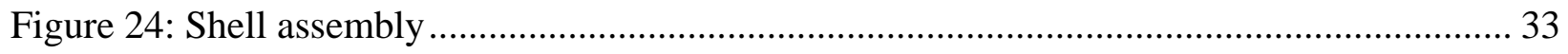

\section{Tables}

Number Description Page

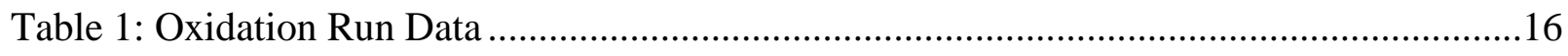




\begin{abstract}
Summary

The Lightning Arrestor Connector (LAC), part " $M$ ", presented opportunities to improve the processes used to fabricate LACs. The A\#\# LACs were the first production LACs produced at the KCP, after the product was transferred from Pinnellas. The new LAC relied on the lessons learned from the A\#\# LACs; however, additional improvements were needed to meet the required budget, yield, and schedule requirements. Improvement projects completed since 2001 include Hermetic Connector Sealing Improvement, Contact Assembly molding Improvement, development of a second vendor for LAC shells, general process improvement, tooling improvement, reduction of the LAC production cycle time, and documention of the LAC granule fabrication process. This report summarizes the accomplishments achieved in improving the LAC Production Readiness.
\end{abstract}




\title{
Discussion
}

\section{Scope and Purpose}

The purpose of the LAC work package projects were to improve Hermetic Connector Sealing, improve Contact Assembly molding, develop a second vendor for LAC shells, improve the LAC manufacturing processes and tooling, reduce the LAC production cycle time, and document the LAC granule fabrication process. Three projects were open at various times to support the improvement efforts: 706500, 703044, and 703010.

\section{Activity / Accomplishments}

\section{Hermetic Connector Sealing Improvement}

\begin{abstract}
Significant hermeticity failures occurred with electrical connectors that use circular stainless steel shell bodies, 9013-type sealing glass, and Alloy 52-type pin contacts. A key design feature in the shell body is a 'd-flat,' which is used to orient the connector in next assembly, and which creates high unsymmetrical stresses. Significant technical requirements for the connector are that they be hermetic after -55 to $+110^{\circ} \mathrm{C}$ temperature cycling and a set of thermal shocks. While this effort analyzed all processes involved, the majority of the effort was directed toward passivation, outgassing, pre-oxidation and sealing. Outgassing of the 304L alloy was determined to be unnecessary and was eliminated. Recommended design modifications, including a glass composition change and location of the sealing glass with reference to certain external shell features, were combined with the processes to be optimized. Using some of the Six Sigma Blackbelt evaluation tools, desired process working spaces were determined. The resulting process and design change improvements from these evaluations were implemented and qualified for production. This paper reviews some of the activities and evaluations performed to achieve an improved and robust hermetic seal under strenuous environmental conditions in electrical connectors with unsymmetrical bodies.
\end{abstract}

\section{Introduction}

The connectors involved were originally designed to include 304L stainless steel circular bodies with EG2164-type sealing glass and Alloy 52-type contacts. A d-flat (shown in Figure 1) in the shell body makes orientation and assembly in next assembly more convenient. However, this dflat creates high unsymmetrical stresses, especially at the center of this d-flat. The change in shape produced a lack of contact in areas between the stainless steel shell sealing surface and the glass. Removing the steel from the glass also revealed no residual glass adherence to the steel, even though the steel shells were pre-oxided before sealing. Pre-oxidation is known to aid in providing a seal ${ }^{1}$. 


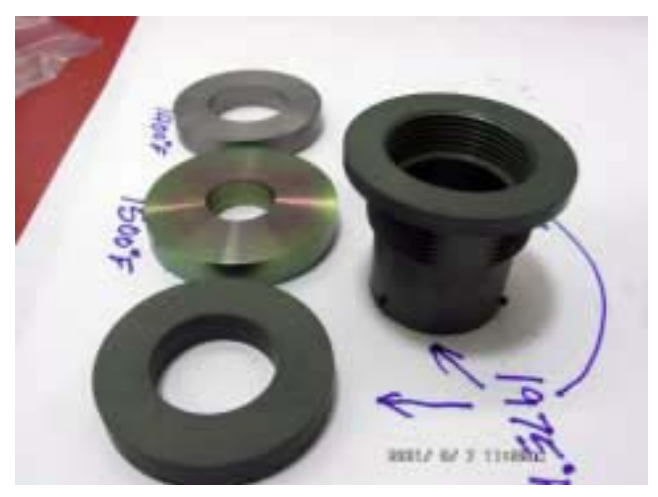

Figure 1: Connector Shell Assembly D-Flat

(c) Honeywell Federal Manufacturing \& Technologies LLC, 2001

This lack of contact resulted in an inability to exceed the $1 \times 10-8 \mathrm{cc} / \mathrm{sec}$ He stp. Typical failures were in the $2 \times 10-8$ up to $1 \times 10-6 \mathrm{cc} /$ second range. Sectioning of the connectors revealed a 'typical v-shaped stain' on the inside surface of the d-flat, as shown in Figure 2a. Soaking the failed connectors in dye penetrant and then reviewing them under a black light usually revealed one or more potential leak paths as shown in Figure 2b. While the parts require temperature cycling, some even failed before temperature cycling. The project objective was, therefore to develop improved pre-oxidation and to obtain residual glass on the steel of a connector when sectioned.

The project was a joint effort between Sandia National Laboratories/New Mexico, ARC Associates of Plymouth, MN, and Honeywell Federal Manufacturing \& Technologies/Kansas City, which is operated for the United States Department of Energy under Contract No. DEACO4-01AL66850.

\section{Original Major Processes Used}

All parts were processed through the following:
A. Cleaning
B. Passivation
C. Cleaning
D. Outgassing
E. Pre-oxidation
F. Sealing
G. Oxide removal
H. Plating
I. Clean
J. Vacuum bake
$\mathrm{K}$. Leak testing 


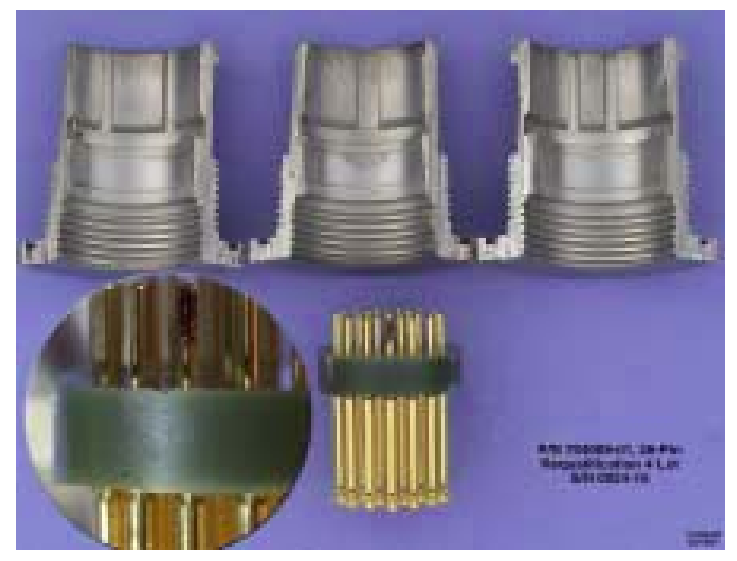

Figure 2a: Stain in D-Flat

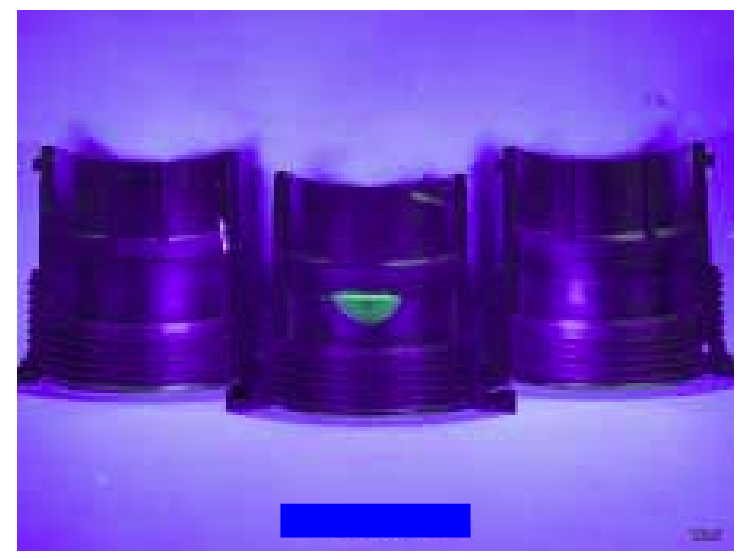

Figure 2b: Stain (Leak Path) Highlighted By Dye Penetrant

After cleaning, the original passivation process was a non-heated nitric acid process followed by another cleaning. Both metal parts, Alloy-52 contact pins and 304L stainless steel shell, were being put through high temperature degassing, which was called 'outgassing.' This process was used to burn off any organics that were present. A belt furnace was used for the oxidation process. The original pre-oxidation process yielded a dark gray to almost black oxide coating.

A belt furnace was also used for the glass sealing or fusing process. The team determined that the original sealing process was slightly reducing or removing the oxide they had worked to obtain. After sealing the connector, the challenge was to remove the chrome oxide. The original process used a heated potassium permanganate/sodium hydroxide ( $\mathrm{KMnO} 4 / \mathrm{NaOH})$ solution to 'loosen' the oxide. This was followed by a heated sulfamic acid solution to 'float' the oxide away. Finally, a heated acid solution was used to 'brighten' the stainless shell. The experiments determined that with the chrome oxide, the sulfamic acid process, so it was deleted. The contact pins are electroplated with gold over nickel following oxide removal. The connector shells were then cleaned and vacuum-baked. The vacuum baking is an attempt to make sure any potential 
leak path is cleared and open during leak testing. Parts were then tested using a Veeco MS-17 leak tester.

\section{Evaluation Approach}

The team's approach was to briefly map the process being analyzed, and from a high level map, pre-oxidation was selected as the process having the greatest impact on providing the desired hermetic seal. Characteristics, process parameters, and measurement systems were determined. A simplified design of experiments (DOE) was determined to find the oxidation extremes in terms of color. Upon determining approximately where to obtain the green oxide produced by chrome, a more complex DOE was used to optimize the oxidation process.

\section{Certain Evaluations}

Surface effect from passivation. As indicated earlier, the 304L stainless steel shells were being passivated using a room temperature nitric acid bath. Heat of approximately $125^{\circ} \mathrm{F}$ was added to the nitric bath. Heated passivation significantly affected the appearance of the stainless steel surface. Little whitish spots were enlarged to approximately four times those at room temperature, as shown in Figure 3. There is some speculation that this change roughens the surface, increasing the leak path distance and providing more sealing surface area for the molten glass to bond.

Process steps include:

- Three water rinses followed by one hot DI rinse

- Blow dry and re-package

- Soak in cleaner $150^{\circ} \mathrm{F}$ for 11 minutes

- Two water rinses

- Passivate in $20 \%$ nitric acid $125^{\circ} \mathrm{F}$ for 20 minutes

- Process conforms to the process specification \#\#\#\#\#\#-\#\#-N, treatment A

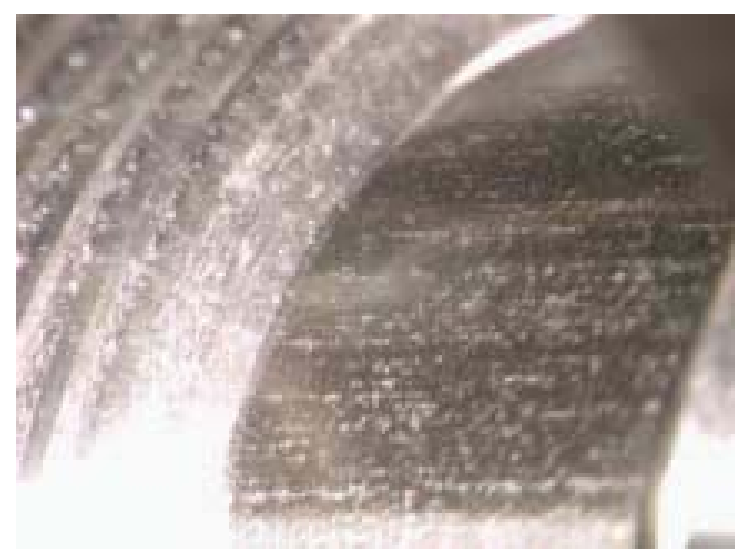

Figure 3: White Spots from Passivation

Outgassing. Outgassing (degassing or decarburization) is a process which puts the piece-part though high temperature to burn off organics. Rulon discusses how stainless steel should be 
degassed for $20-30$ minutes at $1750-1800^{\circ} \mathrm{F}$ in a reducing atmosphere with a dew point of at least $-40^{\circ} \mathrm{C}^{1}$. In this project, stainless steel shells, which were outgassed and then oxided, resulted in a dark gray oxide. A green oxide was obtained when shells were not outgassed. The green is indicative of chrome-oxide. This led us to eliminate the outgassing of stainless steel shells. The Alloy 52 pins continued to be outgassed.

Oxidation. As indicated earlier, the team assessed the need for adequate oxidation as the most critical process. One reference indicates stainless is seldom pre-oxidized, but if desired, this is done by firing to $1800^{\circ} \mathrm{F}$ for 20 minutes in hydrogen or a $10 \%$ hydrogen-nitrogen mix with a dew point of $20^{\circ} \mathrm{C}$ with cooling in the same atmosphere ${ }^{1}$.

The following parameters were determined to be of interest:

1. Type of oxidation,

2. Oxidation thickness, and

3. Oxidation thickness vs. weight gain correlation.

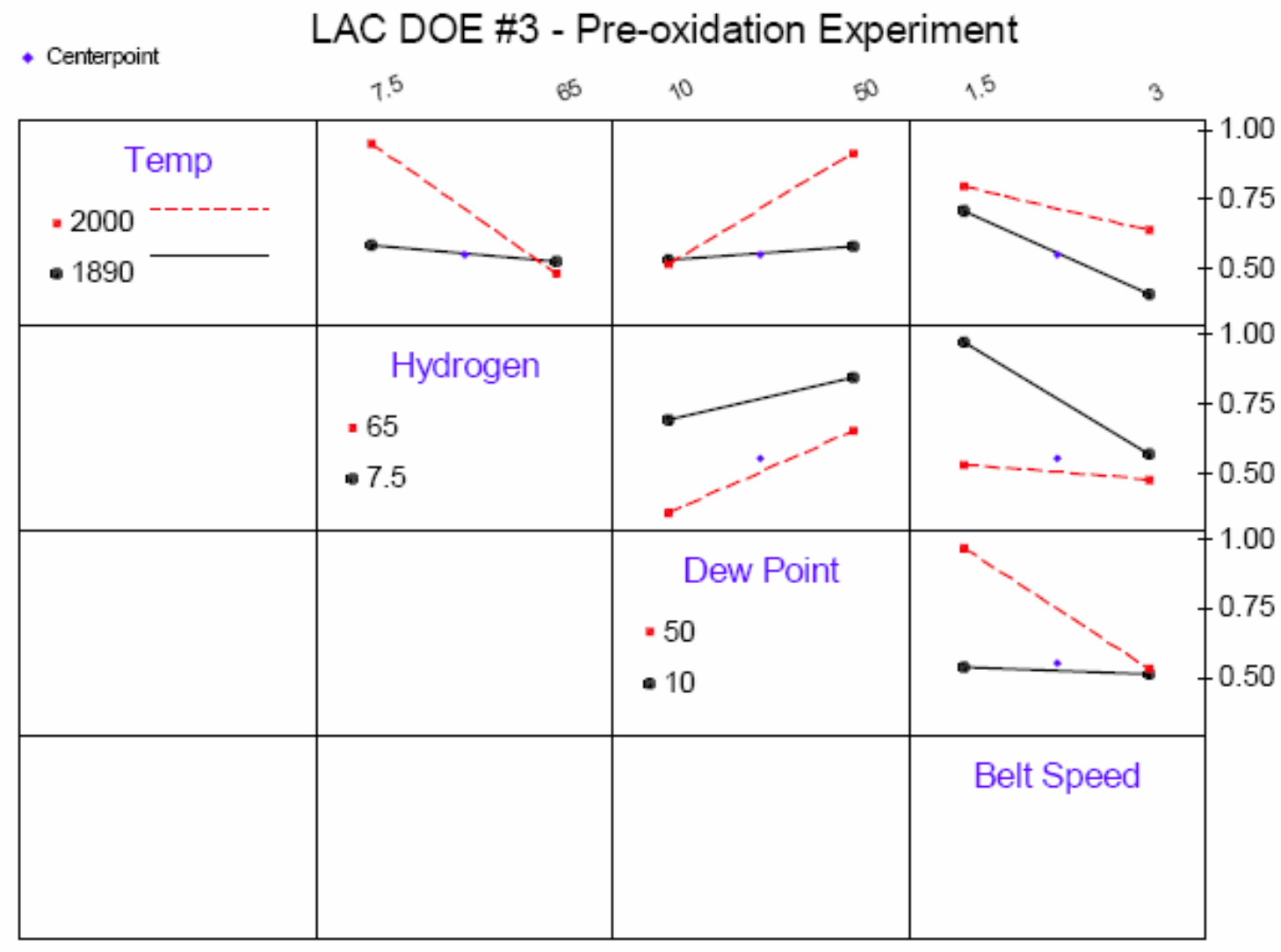

Figure 4a: Pre-oxidation Interaction Plot 
Type. The experts on the team recommended obtaining a chrome oxide, which is green. This was accomplished by varying furnace parameters. The response variable was color. The color could best be judged at the exit end of the furnace, which happened to have a good white light.

Thickness. Some literature indicates that too much oxide can produce a weak seal. The challenge was in obtaining enough oxidation. This was accomplished by slowing the belt speed, which kept the shells in the hot zone longer. A design of experiment with the furnace system being used allowed us to obtain a green chrome oxide. The belt speed in the furnace was somewhat challenged to be in the hot zone long enough to obtain the desired oxidation. The following was a first-cut at providing predictors for oxide thickness based upon data obtained in the recent DOE. The Interaction Plots shown in Figure 4a and Surface Plots in Figure 4b are examples of some of the analyses performed.

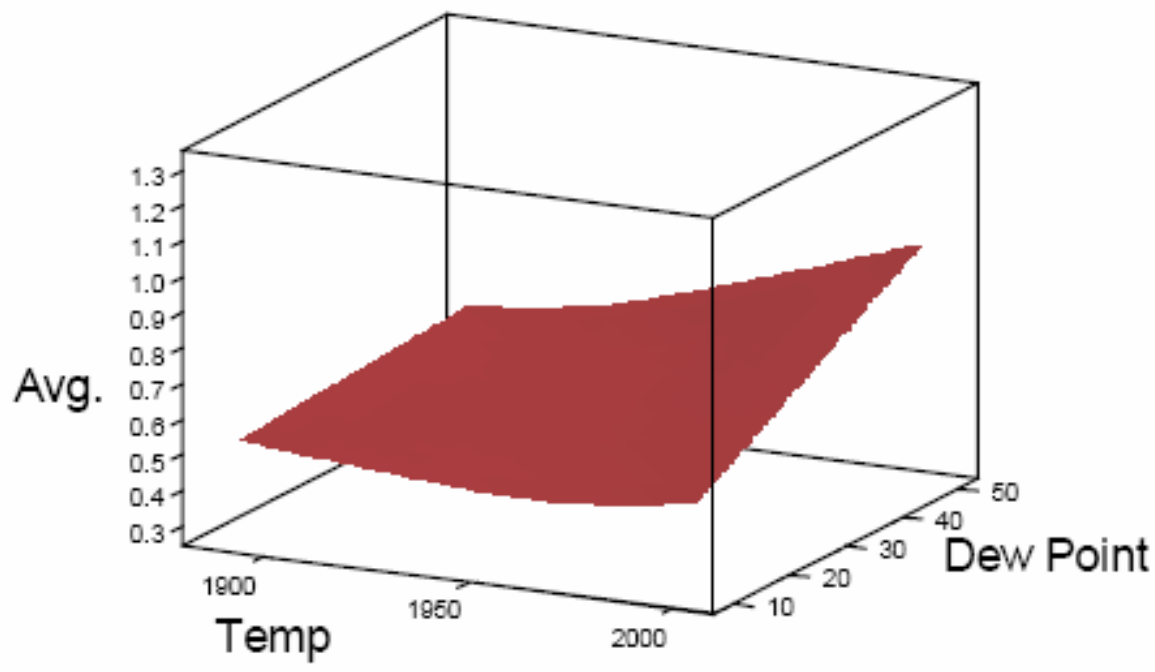

Figure 4b: Pre-oxidation Surface Plot

Some of the conclusions drawn from pre-oxidation and surface plots were

High Temperature - High Dew Point

High Temperature - Low Hydrogen

High Temperature - Low Belt Speed

Low Hydrogen - Low Belt Speed

High Dew Point - Low Belt Speed

From this, one might use High Temperature, High Dew Point, Low Hydrogen and Low Belt Speed. Then, assuming a 0.8 micron minimum oxide thickness is desired, it was estimated that the team should use $1975^{\circ} \mathrm{F}$ or higher, $24^{\circ} \mathrm{F}$ or greater dew point, $2 \mathrm{ipm}$ or slower belt speed and $20 \%$ or less hydrogen. 


\section{Pre-oxidation and Sealing ANOVA}

It was observed that the oxidation on parts seemed to vary tremendously. A preoxidation and sealing analysis of variance test plan was developed and is shown in Figures 5a and 5b. The major objectives here were to compare

1. the amount of time the furnace was stabilized prior to oxidizing,

2. the amount of time the furnace was stabilized prior to sealing,

3. the amount of time to convert from oxidizing to sealing, and

4. the amount of time to convert from sealing to oxidizing.

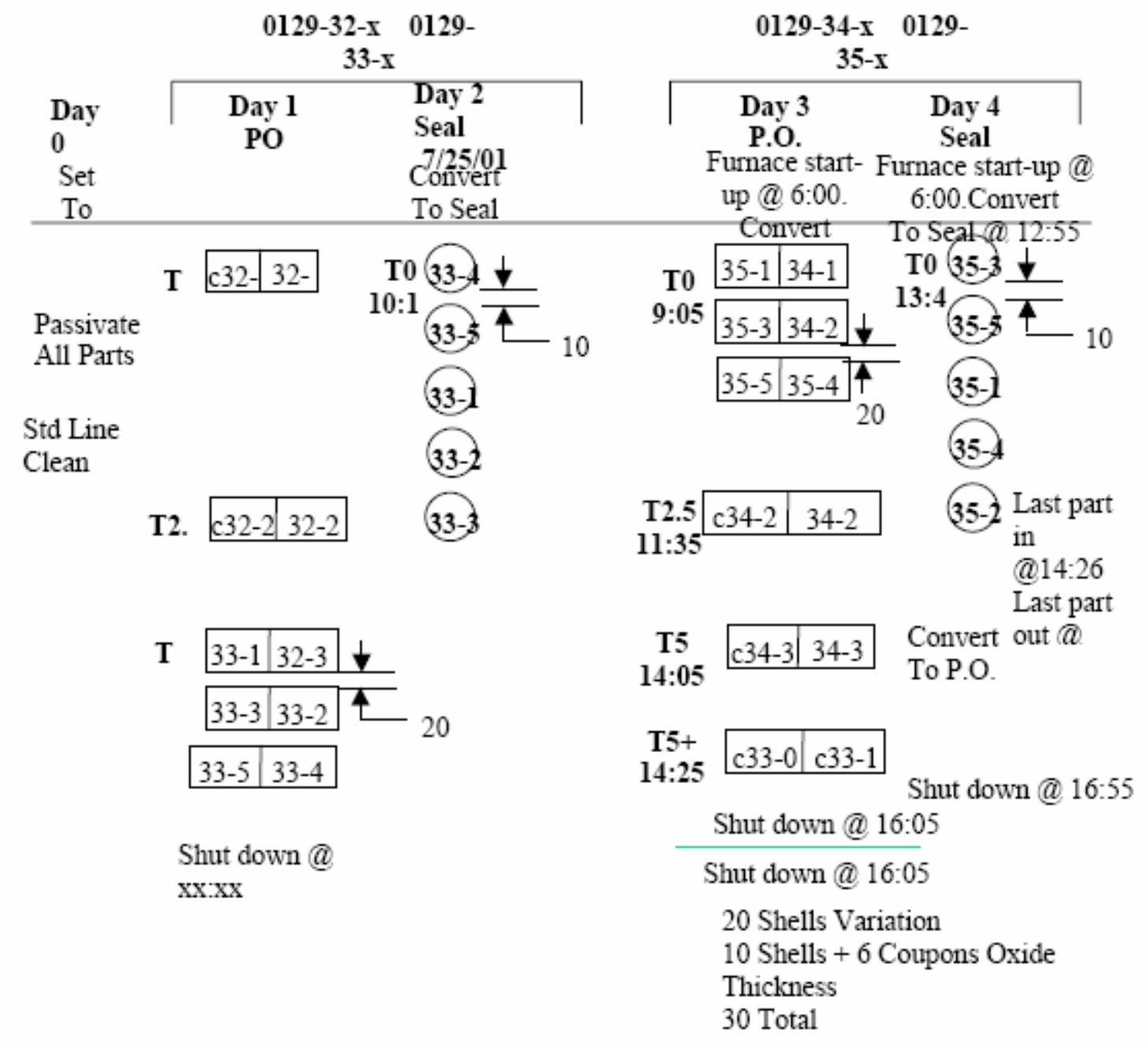

Figure 5a: Day 1 Pre-oxidation Analysis Of Variance

Parts (30 Shells and 15 Coupons) were chosen at random and passivated as a group. Test part serial number markings were scribed on the parts. The plan developed required eight working 
days to complete. Day 0 required us to passivate and standard line-clean the parts. It was decided to clean all parts immediately upon returning from passivation, in an effort to make sure any contamination was removed and would not be allowed to remain and 'harden' on the parts. It would still be required to re-clean parts to be used after 48 hours.

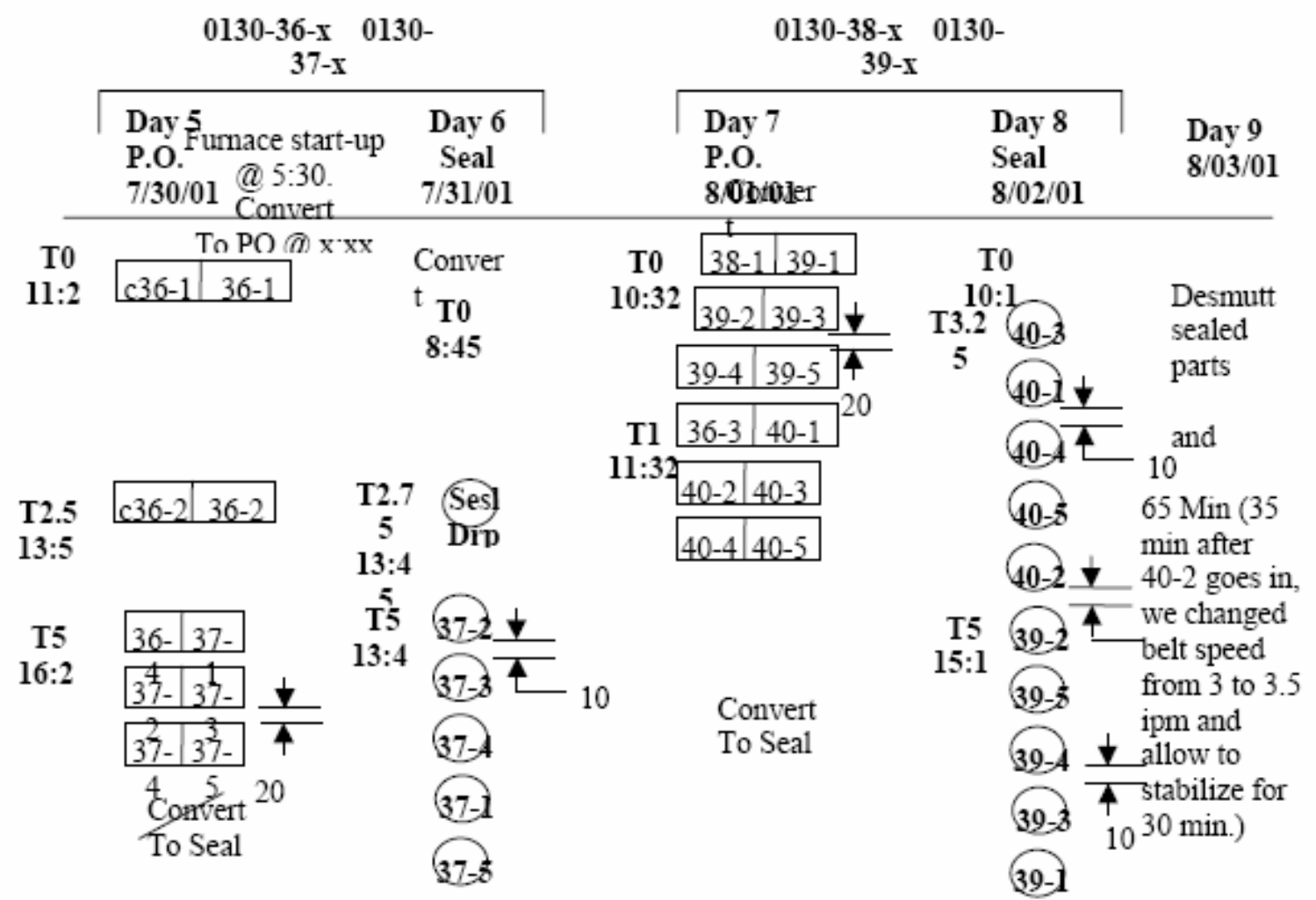

Figure 5b: Day 2 Pre-oxidation Analysis Of Variance

The rectangles represent pre-oxidation and the circles represent sealing. Two rectangles side-byside mean there are either a shell and a coupon or two shells. Shells are noted by ' $S$ ' followed by a number or by just a number. The serial number marked on the part is off to the side. Shells and coupons that are run together, such as those at time T0 on Day 1, have the same serial number marked on them. It was agreed to not run a coupon with the six shell groups, such as time T5 on Day 1, so that the team could maintain the higher confidence level obtained by using five units in the ANOVA. The circles represent shells being sealed.

The result was that the longer times produced better results when converting from sealing to oxidation, when converting from oxidation to sealing, or even when starting from scratch. This is mostly because oxidation has to be cleaned from inside the furnace and off the belt when converting from oxidation to sealing and because much time is required to reach the required dew point. When going from sealing to oxidation, a significant buildup of oxidation is needed 
from which the parts withdraw, requiring several hours. The response variables were oxidation thickness and weight gain.

A sample shell was randomly selected and sent out for oxide thickness measurement. A small scale with 4-place capability was purchased and a measurement system evaluation performed. The scale was found to be very capable with one hundred percent of the variation being attributed to part-to-part variation. The scale was used to weigh shells before and immediately after oxidation. Weight gain has correlated well with oxide measurement thicknesses. Ultimately, the team would like to be able to simply use oxidation weight gain as an in-process gage.

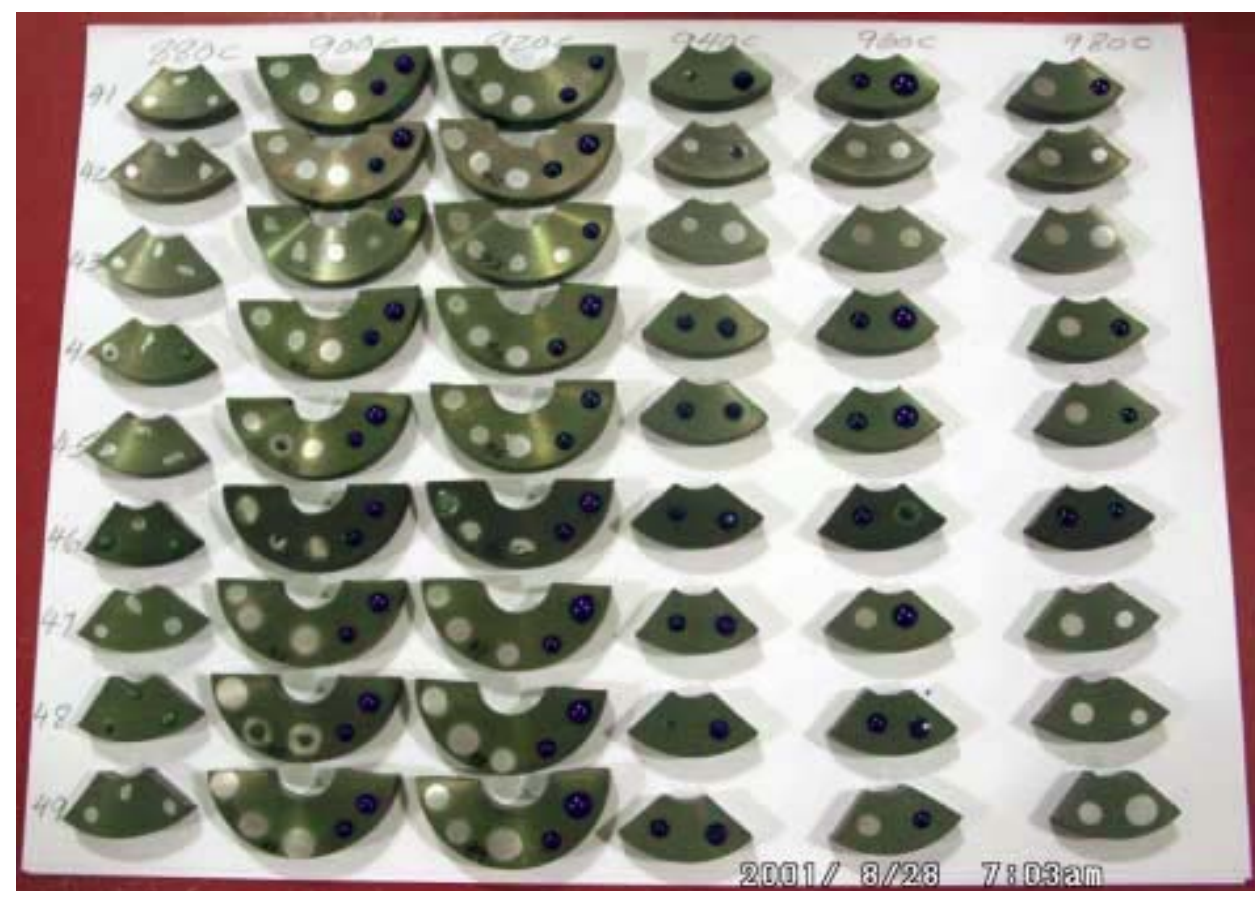

Figure 6: Sessile Drop Tests

Sealing. The team also evaluated the sealing process using sessile drop tests, Figure 6, and design of experiments to optimize parameters. Glass from different sources, including EG2164 and S8061 were evaluated and in all cases, the S8061 glass performed best. The coupons sections with light spots indicate non-adherence tests. Those with dark spots indicate adherence. Rows 41 through 49 represent various oxidation parameters. Columns represent sealing temperatures. Row 46, which used oxidation parameters and sealing temperatures $940^{\circ} \mathrm{C}$ and $960^{\circ} \mathrm{C}$, indicate the best potential parameters.

A Box Plot of the oxide thickness measurements is shown in Figure $7^{2}$. Note that coupon segments \#46 had the greatest oxide thickness and also appeared darkest in Figure 6.

Shell Body to Glass Adherence. The end result was that the S8061 glass adhered better. In fact, it has been consistent enough that the team agreed to an adherence specification in which test 
connectors are sectioned and checked for a 'no stain' condition, and the presence of residual glass is verified, as shown in Figure 8. Glass now has to be 'sprung' out of the section with the major keyway so that the section can be checked for the 'no stain' condition. The team also performed overtesting on a small group of parts to determine robustness.

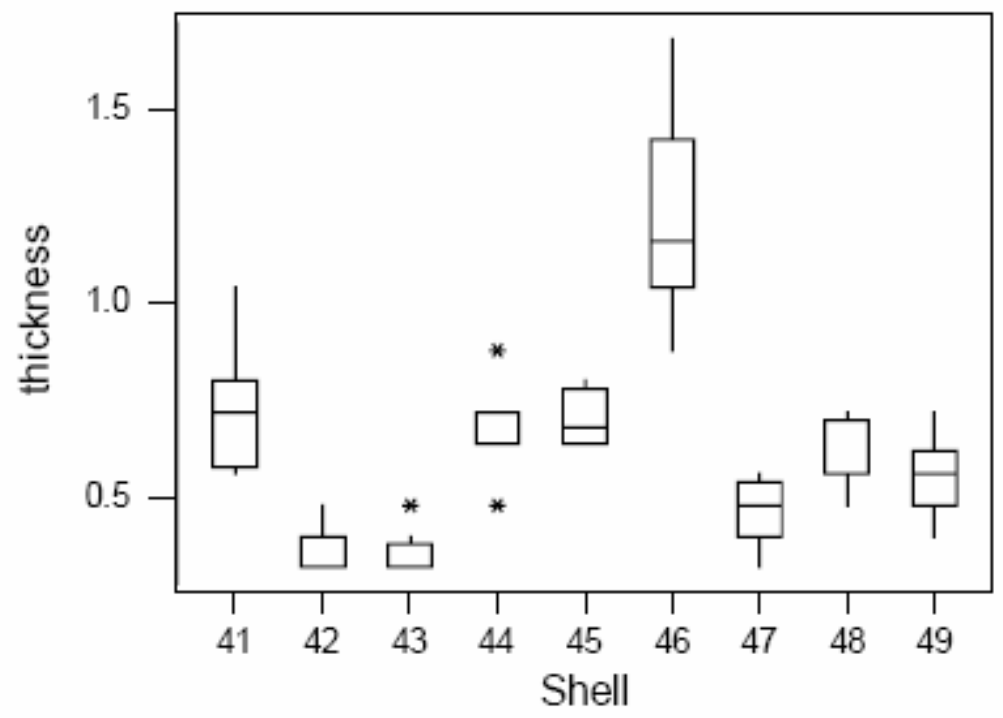

Figure 7: Oxide Thickness for LAC DOE \#3 (Pre-oxidation Experiment) Data from oxide measurements performed at Sandia 


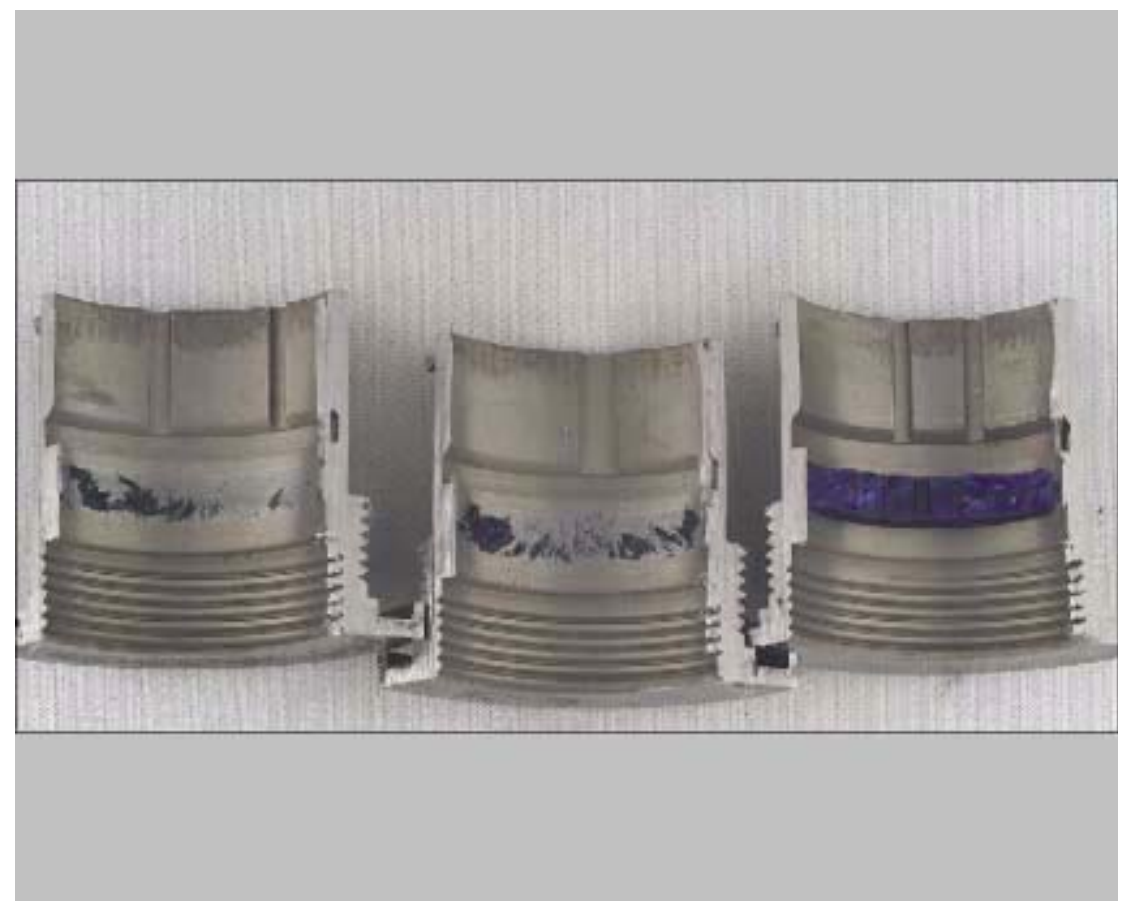

Figure 8: Residual Glass Adherence

Figure 9 is a Pareto Chart of the average effects due to hydrogen, belt speed, dew point and temperature during preoxidation ${ }^{2}$. The Pareto chart indicates hydrogen has the greatest effect, even though it may not be significant (does not extend beyond the plotted reference line).

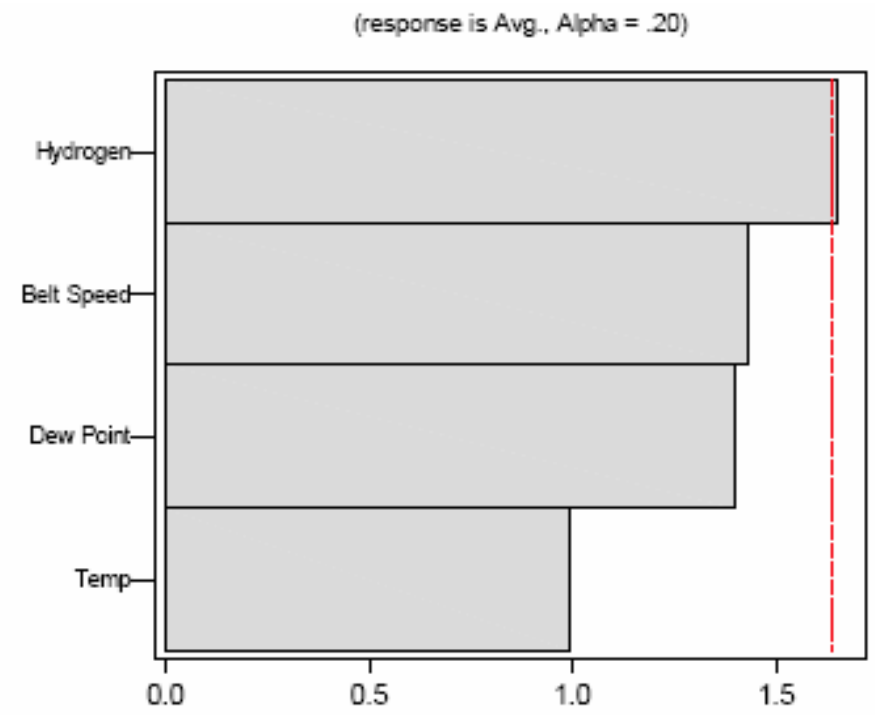

Figure 9: Pareto Chart of the Standardized Effects 
Some of the reasons this project was successful at obtaining a glass to metal seal adherence were:

1. the ability to obtain enough of the right kind of oxide ( 0.7 microns thick chrome oxide), and

2. the ability to seal at conditions that somewhat protected the complete absorption of the oxide into the glass during the sealing process.

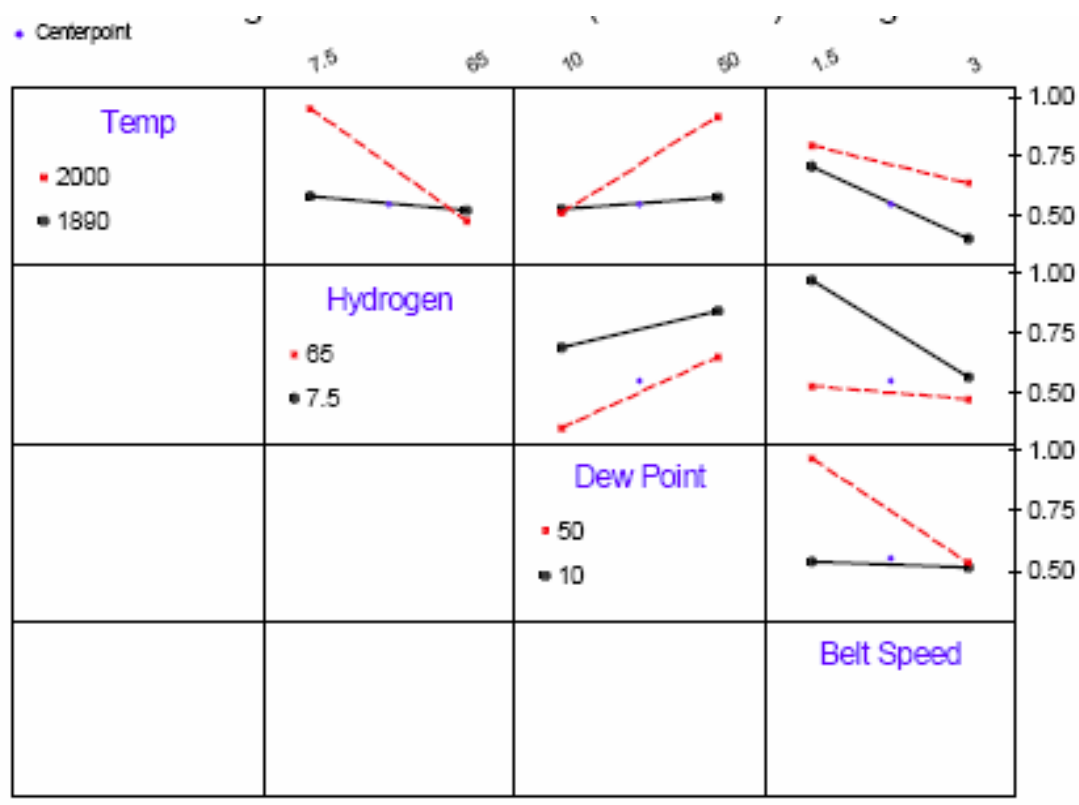

Figure 10: Interaction Plot (data means) for Average

In the Interaction Chart ${ }^{2}$ (see Figure 10), temperature interacts with hydrogen and dew point, and dew point just barely interacts with belt speed for the parameter ranges evaluated. Table 1 displays the average oxidation thickness data, run order, factor settings, etc., for the evaluation ${ }^{2}$.

\begin{tabular}{|r|r|r|r|r|r|r|r|r|}
\hline $\begin{array}{l}\text { StdOrd } \\
\text { er }\end{array}$ & $\begin{array}{l}\text { RunOrd } \\
\text { er }\end{array}$ & Temp & Hydrogen & $\begin{array}{l}\text { Dew } \\
\text { Point }\end{array}$ & $\begin{array}{l}\text { Belt } \\
\text { Speed }\end{array}$ & Avg. & $\begin{array}{l}\text { Std. } \\
\text { Dev. }\end{array}$ & Coupon \\
\hline 3 & 3 & 1890 & 65 & 10 & 3 & 0.35 & 0.05 & 43 \\
\hline 4 & 2 & 2000 & 65 & 10 & 1.5 & 0.36 & 0.06 & 42 \\
\hline 5 & 8 & 1890 & 7.5 & 50 & 3 & 0.46 & 0.08 & 47 \\
\hline 9 & 7 & 1945 & 36.25 & 30 & 2.25 & 0.55 & 0.09 & 49 \\
\hline 8 & 1 & 2000 & 65 & 50 & 3 & 0.6 & 0.09 & 48 \\
\hline 2 & 4 & 2000 & 7.5 & 10 & 3 & 0.67 & 0.13 & 44 \\
\hline 7 & 9 & 1890 & 65 & 50 & 1.5 & 0.7 & 0.07 & 45 \\
\hline 1 & 6 & 1890 & 7.5 & 10 & 1.5 & 0.71 & 0.14 & 41 \\
\hline 6 & 5 & 2000 & 7.5 & 50 & 1.5 & 1.23 & 0.23 & 46 \\
\hline
\end{tabular}

Table 1. Oxidation Run Data 
The Main Effects Plot, as shown in Figure $11^{2}$, displays the response mean for each factor. The effects are the differences between the means and the 'grand mean' represented by the dashed line. All four factors have a large effect on oxidation average. From this plot, the team would select high temperature and dew point, and low hydrogen and belt speed to obtain the greater average oxidation.

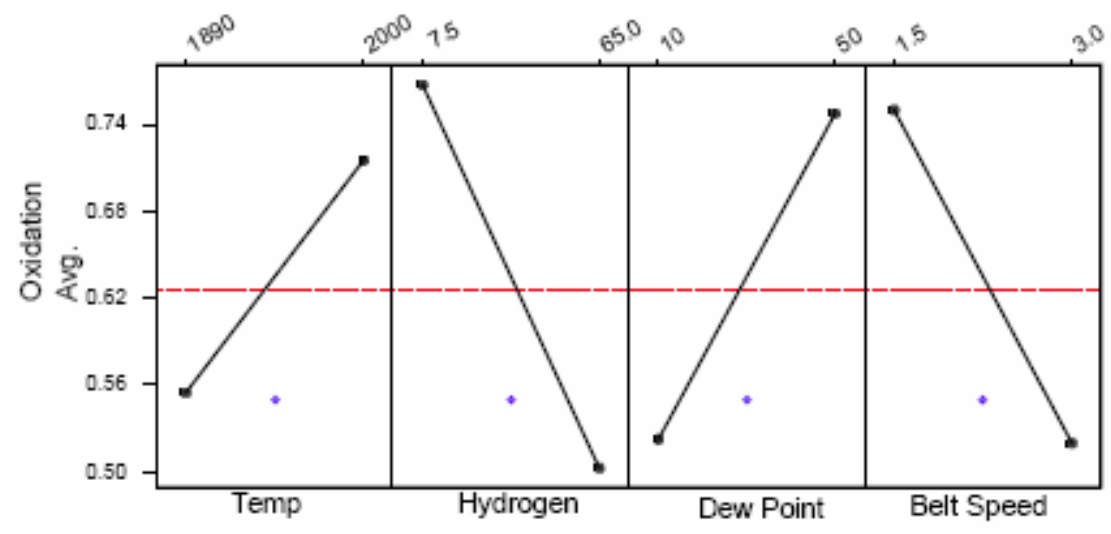

Figure 11: Main Effects Plot (data means) for Oxidation Average

Other Factors. It should be noted that there was a tremendous effect from a set of design changes. As already noted, the S8061 blue glass was important, as was a decrease in final glass thickness and some changes to the stainless shell. However, it was the oxide thickness that was monitored to ensure it had a good seal.

Summary. This project improved a glass to metal seal from one which did not necessarily seal at room temperature to one which withstands a $-55^{\circ} \mathrm{C}$ to $+200^{\circ} \mathrm{C}$ set of temperature cycles and a set of thermal shocks.

\section{General References}

1. R. M. Rulon, Introduction To Glass Science, Proceedings of a Tutorial Symposium --- June 819, 1970; Edited by L. D. Pye, H. J. Stevens, and W. C.

LaCourse; Plenum Press, New York, 1972.

2. D. Krueger, “LAC DOE \#3 Tables and Figures”, September 02, 2001, E-mail. 


\section{4, 703010 LAC Production Readiness}

This project was used to improve the fabrication, inspection, testing, process flow, and tooling used in the "M" LAC manufacturing process. All piece parts were included in the improvement activities. LACs are an expensive part, have a long process flow, and require large amounts of data to meet drawing requirements and material traceability requirements. This project investigated areas to reduce scrap, streamline the process, and reduce paperwork.

The team investigated the molding characteristics of the Contact Assembly, a piece part in the "M" LAC. The investigation led to improved molding yields and changes in the drawing to allow some level of mold flash in the sockets. The evaluations led to an increased yield from $65 \%$ to $80 \%$, and reduced the need for post-mold deburring. A cost savings for the next year of production is estimated to be $\$ 30 \mathrm{~K}$. The following activities were evaluated: bead blasting the mold pins, mold pressure, and new mold pin designs. Replacement mold pins were also fabricated to evaluate the effect of tool wear.

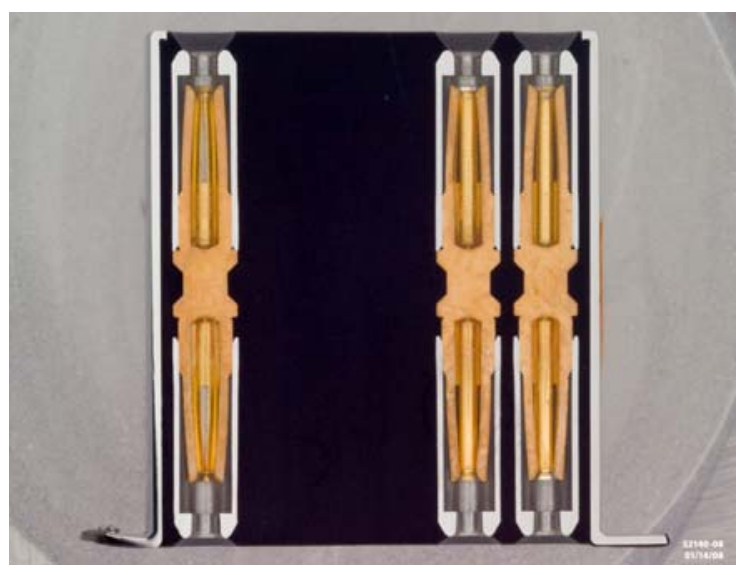

Figure 12: Sockets in the Contact Assembly

The KCP NNR program funded an effort to develop a second qualified vendor for LAC shells. As part of this qualification, a quantity of 20 shells was procured from the second vendor and were built into LACs at KCP and environmentally tested at that level to determine the viability of product built by a second source. Analysis of the electrical data (fast rise breakdown (FRB), insulation resistance, and DC current withstanding) showed the parts performed similarly to the original vendor. A QER was released in January 2008. The QER will allow ARC, a less expensive source, to supply LAC shells.

A computerized template was developed for preprinting the operations on the 1547 production tag. The KCP uses a production record, the 1547 tag, to record operation details as they are completed. Data such as cure times, two person verification, and material lot numbers also reside on the 1547 tag. Completing the 1547 tags is a manual process throughout the plant. The amount of data recorded for the LACs manual process is very long and tedious. The Access 
program prompts the manufacturing personnel for the required data (lot numbers, serial numbers, two-person sign-offs, cure times). The program has resulted in fewer ROA errors, improved accuracy of the required data, and allowed faster completion of the tags. The pre-printed tags have also improved the inspection process, which has to verify the data on the 1547 production tags. See Figure 13 for an example of the template.

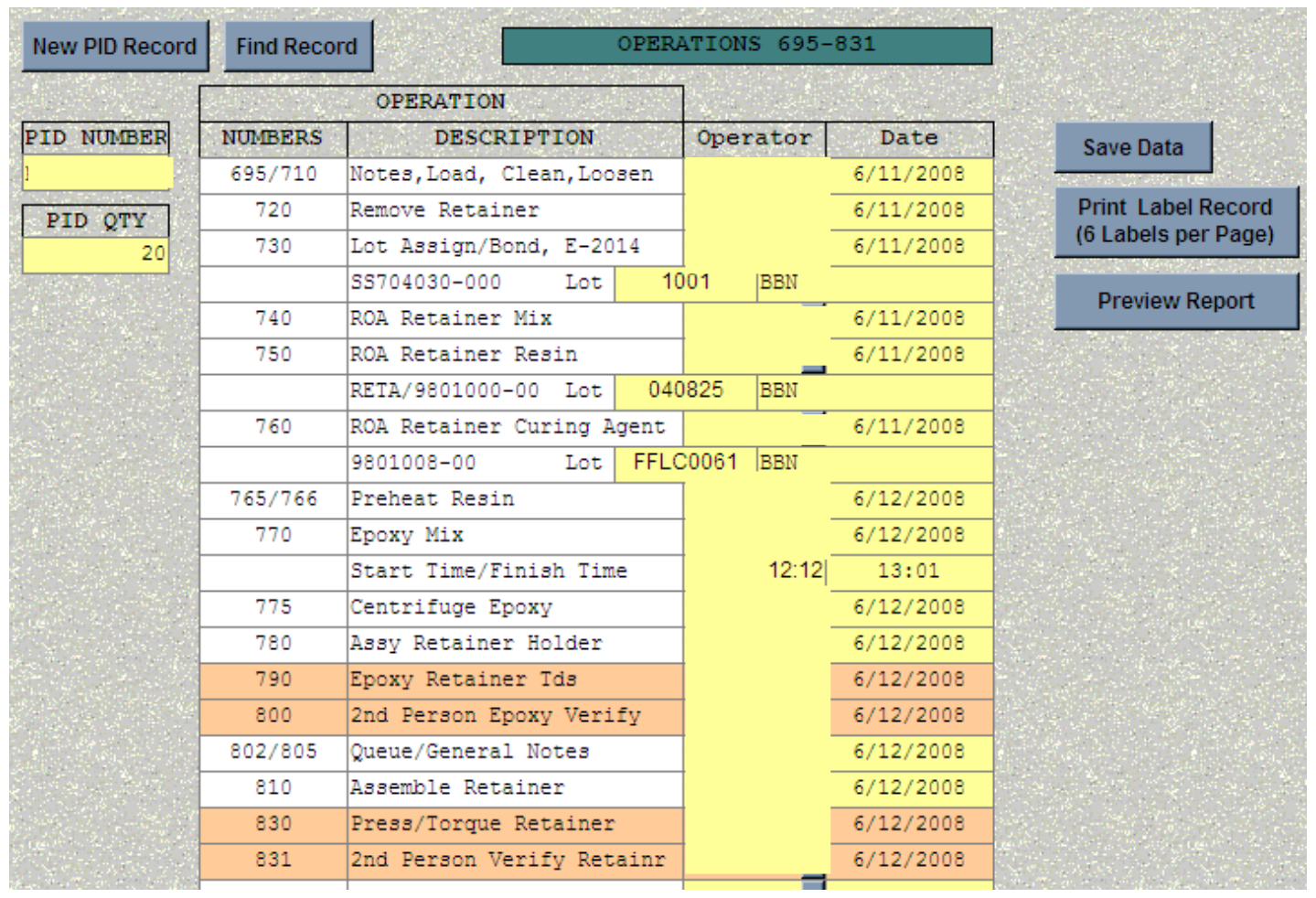

Figure 13: Data Input Screen 


\begin{tabular}{|c|c|c|c|c|}
\hline Op No. & \multicolumn{2}{|c|}{ Operation Description } & Assoc. \# & Date \\
\hline $695 / 710$ & \multicolumn{3}{|l|}{ Notes, Losd, Clean, Loosen } & $6 / 11 / 2008$ \\
\hline 720 & \multicolumn{3}{|l|}{ Renove Retainer } & $6 / 11 / 2008$ \\
\hline \multirow[t]{2}{*}{730} & \multicolumn{3}{|l|}{ Lot Assign/Bond, E.2014 } & $6 / 11 / 2008$ \\
\hline & 95704030.000 & 10 & BEN & \\
\hline 740 & \multicolumn{3}{|l|}{ ROA Retainer Mix } & $6 / 11 / 2008$ \\
\hline \multirow[t]{2}{*}{750} & \multicolumn{3}{|l|}{ ROA Retainer Resin } & $6 / 11 / 2005$ \\
\hline & RETA/9801000-00 Lot & 040 & BEN & \\
\hline \multirow[t]{2}{*}{760} & \multicolumn{3}{|c|}{ ROA Retainer Curing Agent } & $6 / 11 / 2008$ \\
\hline & $9601008 \cdot 00$ & $\mathrm{FFLC}$ & \begin{tabular}{l|l|}
061 & $\mathrm{BBN}$ \\
\end{tabular} & \\
\hline $765 / 766$ & \multirow{2}{*}{\multicolumn{3}{|c|}{\begin{tabular}{|l|} 
Preheat Resin \\
Epoxy Vix
\end{tabular}}} & $6 / 12 / 2008$ \\
\hline \multirow[t]{2}{*}{770} & & & & $6 / 12 / 2008$ \\
\hline & Start Tine/Finish Tine & & $12: 12$ & $13: 01$ \\
\hline 775 & \multicolumn{3}{|l|}{ Centrifuge Epoxy } & $6 / 12 / 2008$ \\
\hline 780 & \multicolumn{3}{|l|}{ Assy Retainer Holder } & $6 / 12 / 2008$ \\
\hline 790 & \multirow{2}{*}{\multicolumn{3}{|c|}{\begin{tabular}{|l|} 
Epoxy Retainer Tds \\
2nd Person Epoxy Verify \\
\end{tabular}}} & $6 / 12 / 2008$ \\
\hline 800 & & & & $6 / 12 / 2008$ \\
\hline $802 / 805$ & \multicolumn{3}{|l|}{ Queue/General Notes } & $6 / 12 / 2008$ \\
\hline 810 & \multicolumn{3}{|l|}{ Assenble Retainer } & $6 / 12 / 2008$ \\
\hline 830 & \multirow{2}{*}{\multicolumn{3}{|c|}{ Press/Torque Retainer }} & $6 / 12 / 2008$ \\
\hline 831 & \multicolumn{2}{|l|}{ 2nd Person Verify Retainr } & & $6 / 12 / 2008$ \\
\hline
\end{tabular}

Figure 14: 1547E Printed Label

Activities included the following:

- Developed an alignment tool used during contact resistance testing to maintain pin integrity during testing. The Connector Shell Assembly and the final "M" LAC part levels get a resistance test. The fixture engages both ends of the LAC. The solder pins are not always perfectly aligned, which would cause difficulties when engaging the test adapter. A plastic alignment tool was designed to align the pins for loading in to the adapter.

- Redesigned handling fixtures to prevent pin damage. The previous handling fixtures exposed the solder pins, which lead to bent and damaged pins. The fixtures were redesigned to include a removable Plexiglas lid which covers the solder pins.

- Reviewed and completed the initial nuclear safety requirement maps for all piece parts, material specifications, and process specifications.

- Supported a nuclear safety review. Twenty-nine LAC drawings and specifications were reviewed.

- Identified the source of voltage leaks during particle detection testing. Experiments were conducted to determine the source of the current leaks. The phenolic material used for the test adapters was a different grade of phenolic than previous adapters. The newer phenolic was a lesser grade which absorbed moisture from the air more readily.

- Developed alternate epoxy material for use in mounting the D-test samples from the Web Disc Assembly. The material previously used was a difficult to acquire frozen epoxy film.

- Developed disassembly tooling which can be used to nondestructively disassemble a LAC needing failure analysis or rework performed

- Developed an Environmental Hood removal tool in response to a design change. The Hood removal tool is similar to a manual can opener. 
- Developed routings for separate D-test part flow for the Web Disc Assembly, Connector Shell Assembly, and LAC. The separate routings reduced the paper work (1547 tags), and improve visibility on the D-test units.

- Supported the LAC QE and first production unit builds with engineering support including routing reviews and pre-QAIP reviews.

- Performed electrical data analysis for 3 testers, PT3300, PT3665, and PT3739 for the design agency. This activity lead to successful qualification of all three testers.

- Performed failure analysis that lead to a specification change. The LAC had been tested at a voltage of 500 volts. A PPI failure investigation revealed the test voltage can approach the designed breakdown voltage (FRB) of the LAC. Working with the design agency product engineer and systems, the specification was changed to a test voltage of 400 volts. No further failures have occurred.

- Provided support for the qualification of \#\#\#49-01, \#\#\#51-02 and \#\#\#\#1-01 connectors (J1, J2 and J3 Fireset connectors) at Amphenol following the flood at that facility.

- Developed a process to insure the Inner-Disc's "feet" do not protrude outside the outer surface of the Web while bonding.

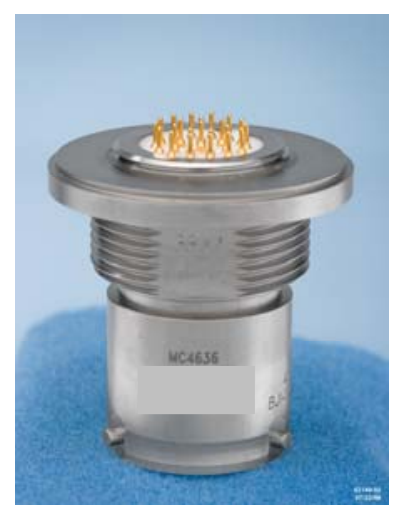

Figure 15: “M” LAC 


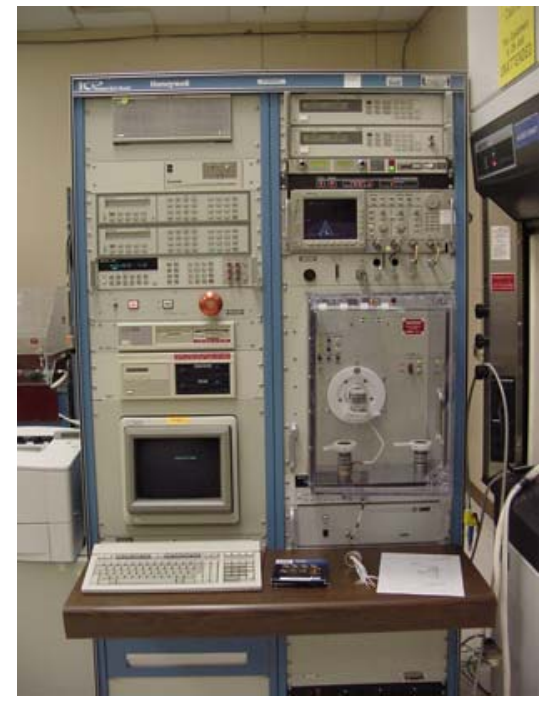

Figure 16: PT3665, FRB Tester 


\section{LAC Granule Knowledge Preservation}

The KCP fabricates LAC Granules only a few times a year. The one Subject Matter Expert (SME) that refined the LAC Granule process and produces the LAC Granules could retire soon, and the KCP could lose the critical and tacit knowledge of this SME. The Knowledge Preservation (KP) team captured the critical process and product information about the LAC Granule fabrication at KCP using Six Sigma process mapping, documents, SME interviews, video-taping, and animations. The KP team processed the captured information and delivered a Knowledge Preservation product in a web-based format. Users access information through the FM\&T Intranet web (the Portal).

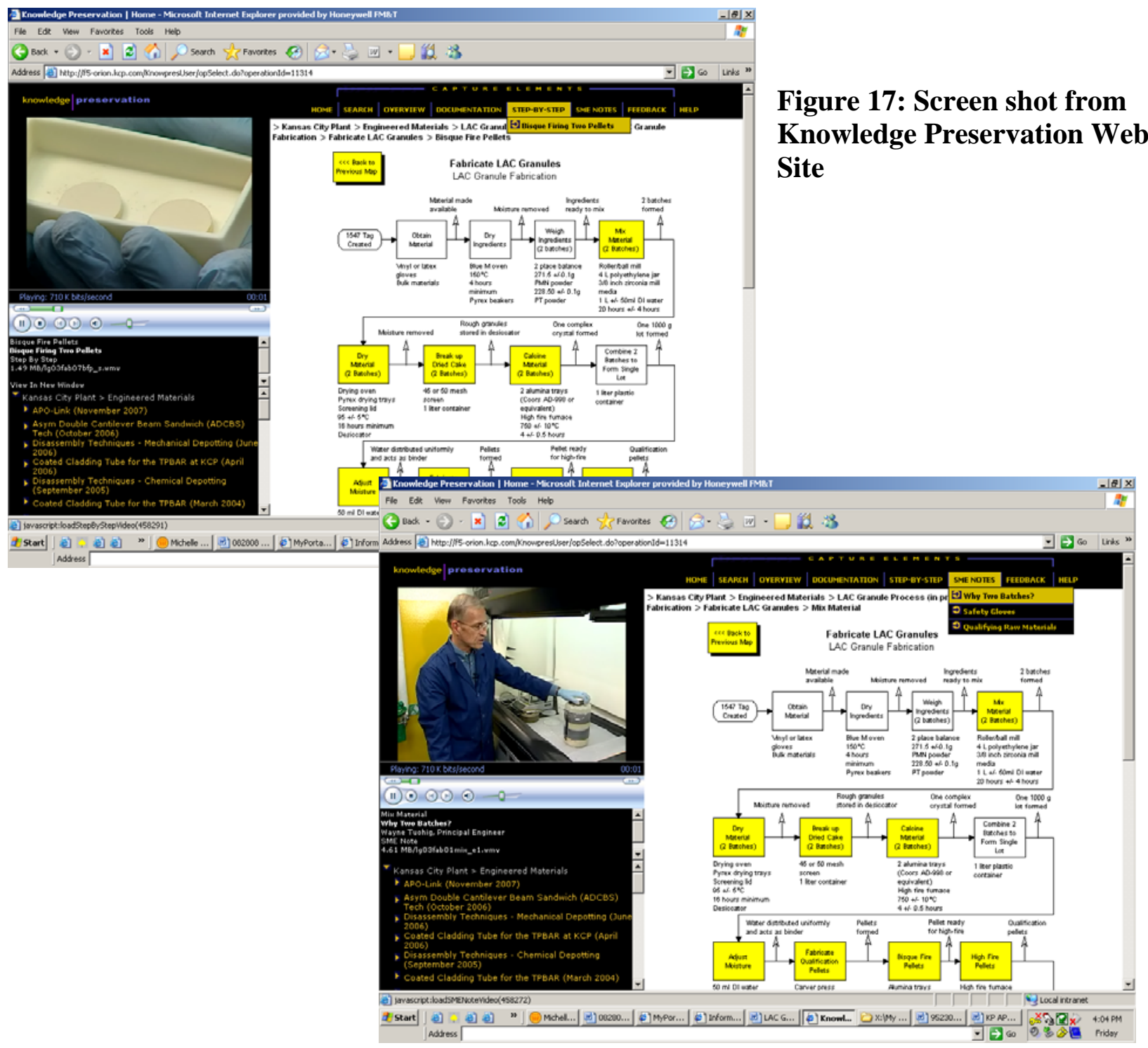

Figure 18: Screen shot from Knowledge Preservation Web Site 


\section{LAC Shell Second Vendor Activities}

A second LAC shell supplier was developed to provide a second and less expensive source of LAC shells than the primary supplier. "S" LAC shells were procured from the second source for evaluation. Qualification and margin testing were performed on the shells, as well as building a group into LACs for using assembly qualification testing.

Group I "S" LAC shells from Arc Associates were qualification and margin tested at KCP. A second group of "S" LAC shells was purchased and submitted to qualification testing. Qualification testing consisted of hermeticity, electrical, ultrasonic inspection, temp cycle, temp shock, hermeticity, electrical, ultrasonic inspection, shock and vibe sequence, hermeticity, electrical, ultrasonic inspection, and glass adherence. The ARC shells passed all development, qualification and margin testing successfully and an acceptable QER for "S" LAC shells from Arc Associates has been released.

\section{Cost Savings}

The qualification of ARC as a second LAC shell vendor will result in a significant cost savings over the life of the program. The cost savings for the program is approximately $\$ 3,165,545$. The assumptions are noted below. MicroMode, MM, is the original qualified LAC shell vendor.

$\begin{array}{lll}\text { Est. program cost from MM } & \$ 9,101,782 & \\ \text { Est. program cost from ARC } & -\$ 5,464,102 & \\ \text { Cost of ARC shells for 1 yr } & -\quad \$ 215,310 \quad \text { (bought for WR while qualifying } \\ & -\$ 256,825 & \text { ARC) } \\ \text { Cost of ARC qualification } & -\quad \$ 2 & \end{array}$

Net savings

$\$ 3,165,545$ 


\section{LAC Pin Placement Verification System}

\section{Summary}

The LAC Pin Placement Verification System (PPVS) was developed during FY07 as a continuation of the ADAPT project. The LAC PPVS was conceived with the intention of eliminating ambiguity and obtain repeatable results when performing verification of lightning arrest connectors. Current verification tools employ mechanical jigs to test for $\mathrm{pin} / \mathrm{hole}$ concentricity and web placement. A non-quantitative test result is obtained by placing the jig over the unit under test and the operator performing a good/bad subjective test ("how good it fits"). This test does not provide results based on comparative analysis, but rather in operator subjective opinion therefore limiting its quality control value. The LAC PPVS addresses these deficiencies by providing test results based on pre-established tolerance parameters. Operator subjectivity is eliminated by using a set of fixed references for each measurement, thus reducing variability in the results and providing positive pass/fail results.

\section{Original Requirements}

The original requirements for the LAC PPVS were not completely defined. The fundamental purpose of the LAC PPVS was to substitute the mechanical jig testers and manual operator examination used for eccentricity/concentricity verification of the following parts:

- 5 Pin connector

- 22 Pin web disc assembly

- 22 Pin shell with web disc

No numerical tolerance specification was defined since the jigs only provide a non-numerical pass/fail result. Tentatively, the new tool would provide a measurement resolution of 1 micron, but this number was rejected after considering it unfeasible. At the end it was agreed that the system operator should be able to adjust the tolerance as desired, up to the maximum resolution of the optical system. Tolerance specifications will be later developed for each of the tested parts. No other requirements were provided.

\section{Functional Characteristics and Specifications}

The following requirements were created to work as reference for development work as well as later system validation:

- Optical system capable of verifying pin and web assembly placement as per design tolerances up to 0.001 " with positive "Pass" or "Fail” indication and visual representation.

- Adjustable tolerance margin.

- Image and results saving capabilities for reporting.

- Modular design with flexibility to incorporate new parts as needed.

- Capable of repetitive results independent of part positioning and ambient illumination conditions. 


\section{System Description and Functionality}

Figure 19 depicts the LAC PPVS prototype. It consists of the optical unit, part holding jigs and computer system. The optical unit subsystem consists of a CCD camera (Allied model Oscar F810C), 0.125X telecentric lenses (Edmund Optical 55348), axial diffuse illuminator (Advance Illumination model DL2449) and mounting mechanisms. The part holding jigs comprise the swivel base, the 5 pin connector holder and the web assembly holder. The computer used in this prototype was a Dell Inspirion 9400.

Optical System. The main component of the LAC PPVS optical system is the telecentric lenses. These types of lenses are immune to the image defects that occur in conventional lenses when tubular type objects are examined. The lens assembly provides for focal and aperture adjustments for system calibration. Illumination is provided by a low voltage diffuse illuminator (red light). Images are captured by the top mounted firewire CCD camera.

Holding Jigs. Figure 20 depicts the three types of inspected parts along with their respective holding jigs. The 25 pin shell with web connector does not have a separate jig since it is an integral part of the swivel unit.

Computer System. The computer used for this prototype was a Dell Inspirion 9400. Any other computer can be used for this purpose for as long it is capable of running the application software.

The application software was developed in LabView 8.2. It consists of a Graphical User Interface (GUI), inspection module and processing engine (see Figure 21). The inspection module resides inside the processing engine and contains the specific inspection program for a particular part. A set of rules govern the data input and output format for this module. The Processing Engine provides the necessary information for the Inspection Module to perform the verification of a particular part. The way the Inspection Module process this data is transparent to the processing engine, for as long the data input and output format are followed. This configuration allows the inspection process to be as elaborate and complex as desired and at the same time provides the capability of adding new parts without any main program modification. The verifications can be written by expert personnel and then incorporated to the program to be used by non-expert users. 


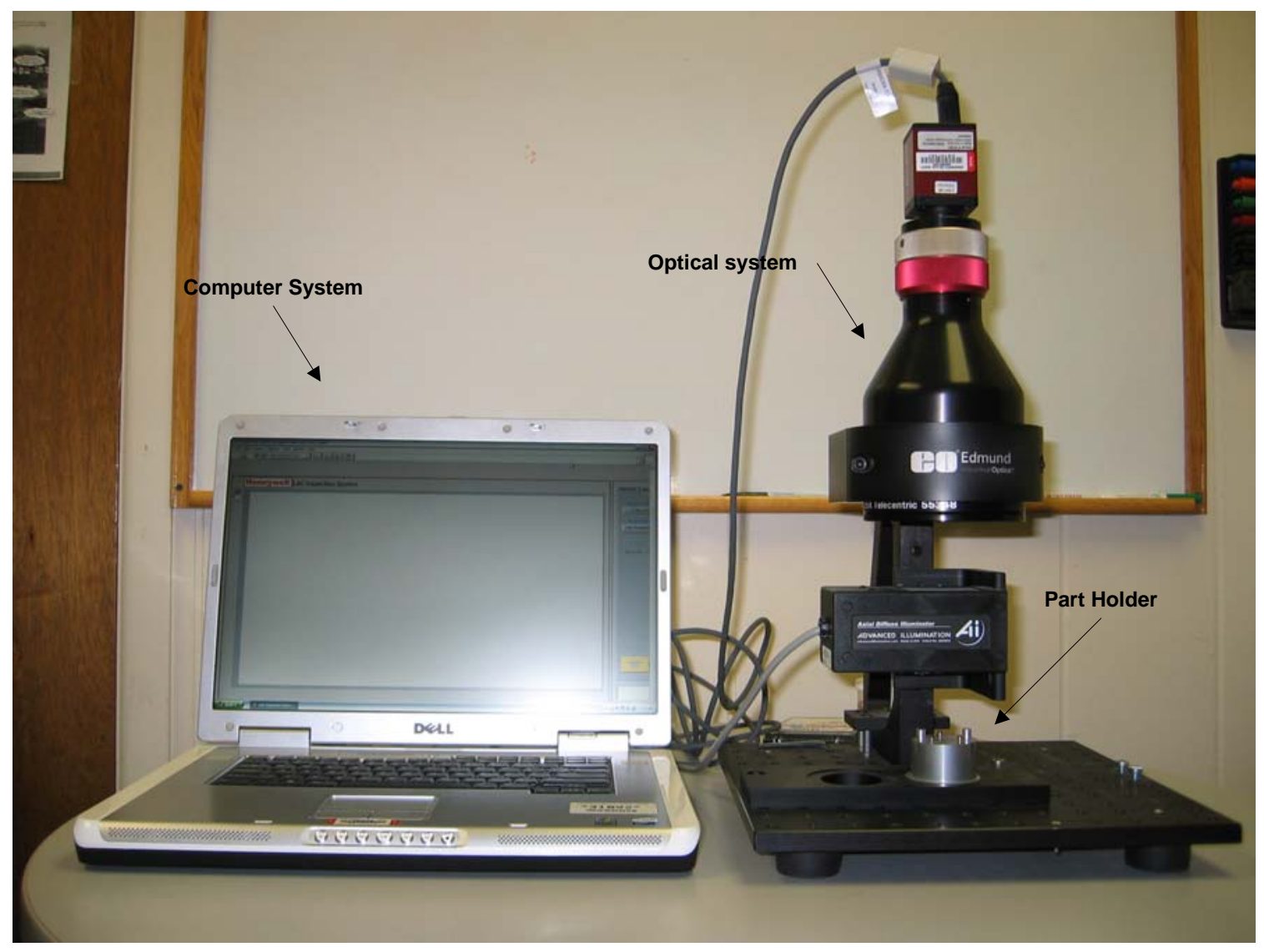

Figure 19: LAC Pin Placement Verification System

The GUI provides the input and output interface for the user to select what parts to verify and observe the verification results. It also provides the necessary controls for calibration and adjustments, as well as data recording and retrieval. 


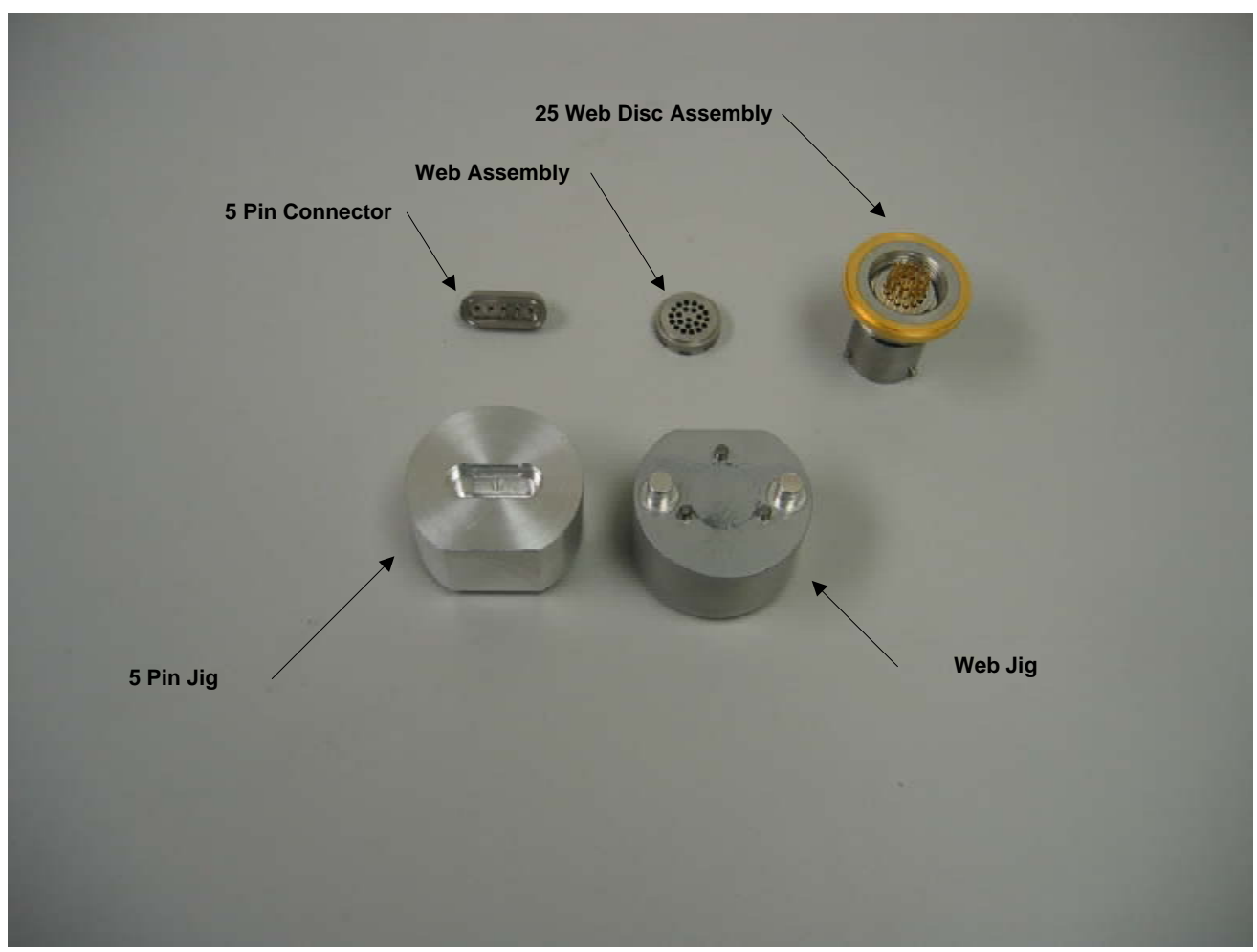

Figure 20: Parts and holding Jigs

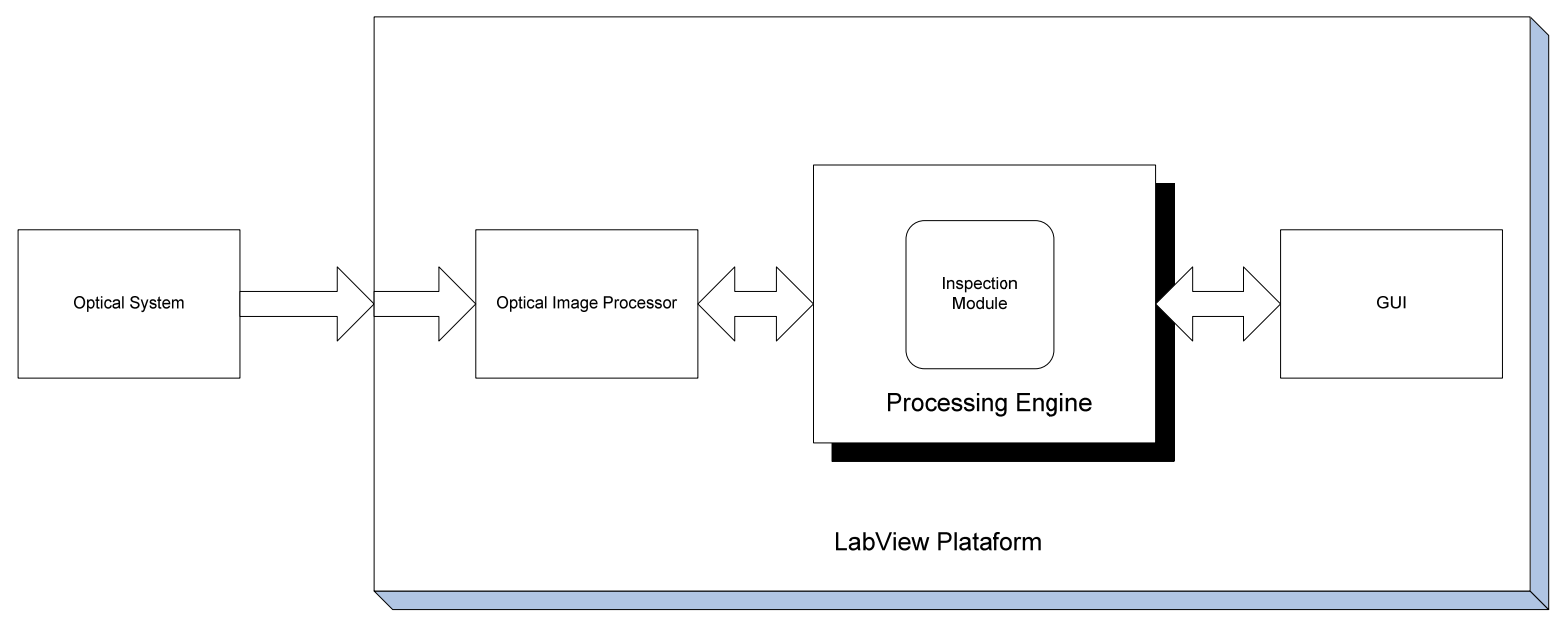

Figure 21: System simplified block diagram

\section{System Operations}

System operation has been automated as much as possible. After an initial one time calibration, the user is only required to select and place the unit under test and run the verification as follows: 
1. At the GUI, the user selects the part to be verified.

2. The user selects either a live image or a previously saved image for testing.

3. The user places the part to be verified at the corresponding jig.

4. If the live image is selected, the image is acquired by clicking at the GUI control or by pressing F1.

5. If the image is acceptable, then it can be verified by clicking at the GUI or by pressing F2.

6. In case of a previously saved image, the Acquire step is skipped.

7. The results are displayed at the GUI.

\section{Test Results}

Figure 22 represents a GUI screen shot for a 5 pin connector verification. Figure 22.1 represents the one detail of this verification. The pas/fail results are obtained by measuring the distance between the center of the pin and the center of the hole.

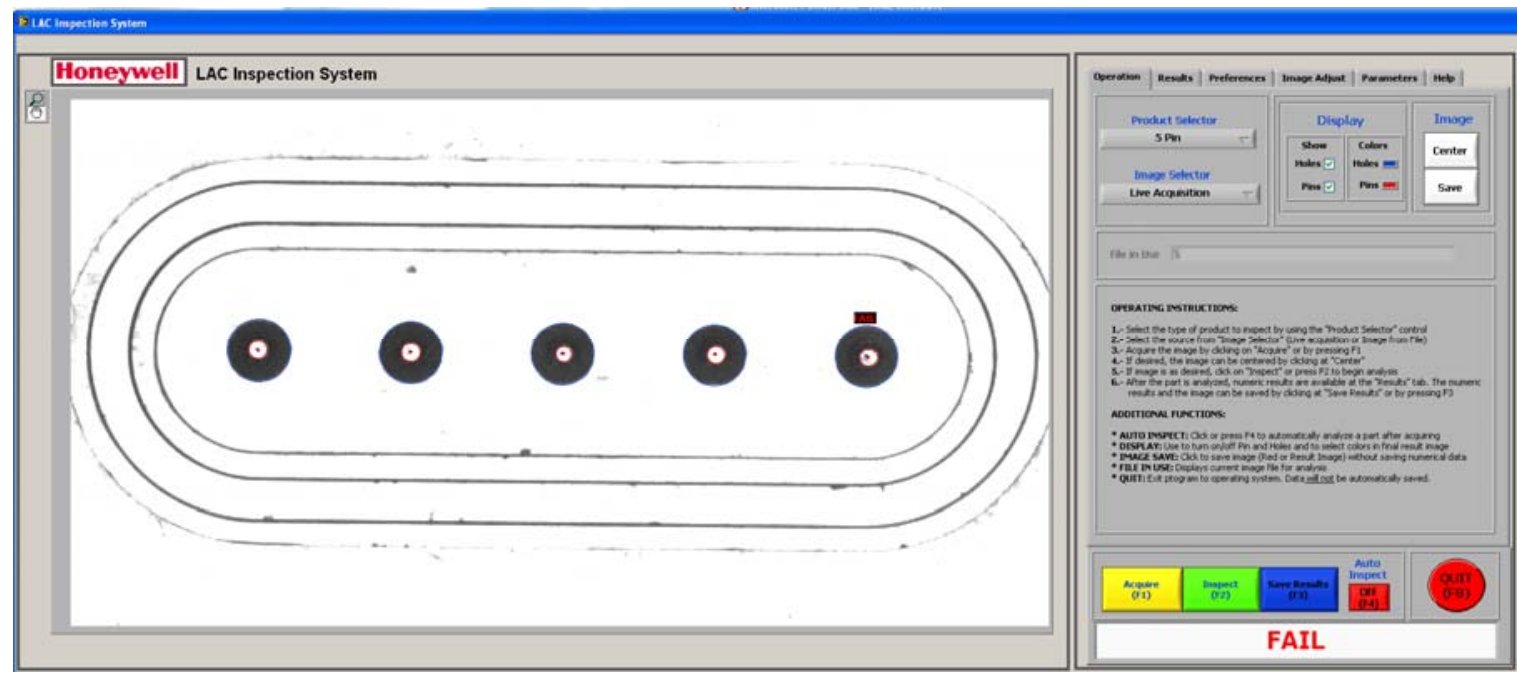

Figure 22: LAC GUI screen shot

This distance can be measured in pixels or inches. The user can decide if the inspection is acceptable by examining the concentricity of the red and the blue circles. The measurement values are then tabulated and compared with the user defined tolerance. Figure 23 represents the tabulated analysis results for a 22 web disc. For the web disc, the computer will measure the concentricity of the web/disc assembly. Figure 23.1 details this analysis: The disc holes can be seen as the clear part of the picture whereas the web appears as dark.

Figure 24 demonstrates the results obtained when analyzing a 25 pin shell assembly. 

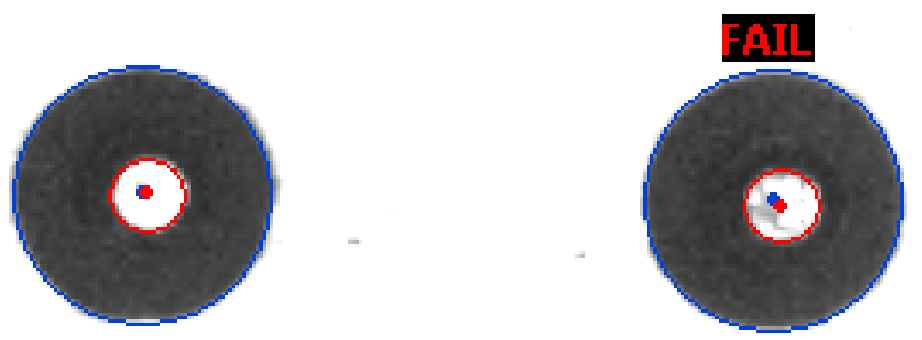

Figure 22.1: Pin/Hole detail

\section{Project Status}

A prototype test unit was completed and delivered for testing July 2007. Evaluation of this prototype found the following issues:

1. Adding a new inspection requires modifying the processing engine to add the new part number. This operation should not require any source code modification.

2. In some occasions, the inspection system failed to recognize a pattern and no measurements are possible. This problem is usually solved by re-orientating the part and repeating the acquisition.

3. The system requires some warm-up time before it can produce consistent results.

4. System calibration was complicated and not robust.

5. System locks-up under certain key combinations.

Despite the above described issues, the system was able to give useful results in 9 out of 10 tests. The 10\% failures were distributed between acquisition failures and system lock-ups, no erroneous measurements.

Kansas City Plant was commissioned to perform further testing and to provide with pass/fail tolerances. 


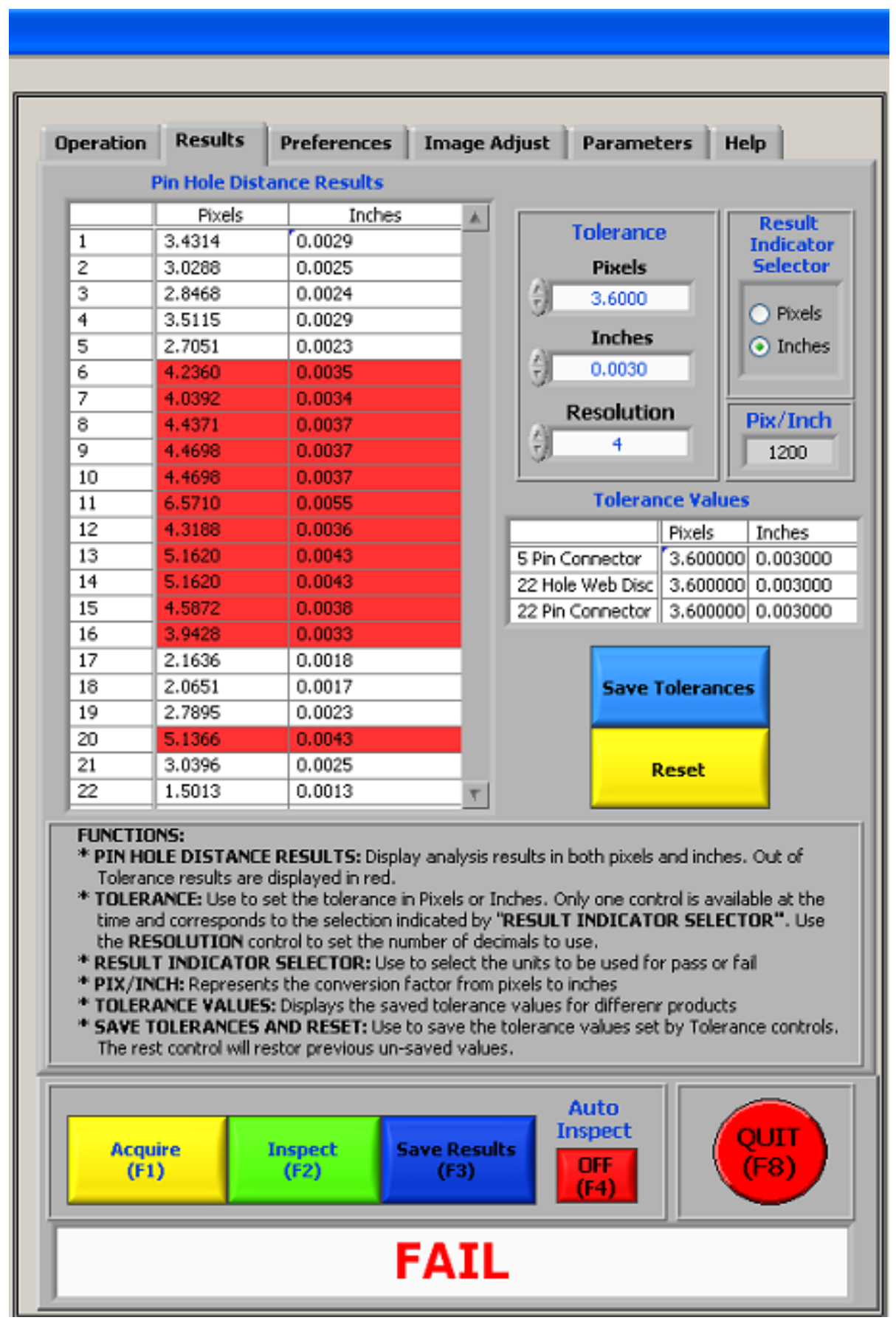

Figure 23: Web Disc tabulated results 

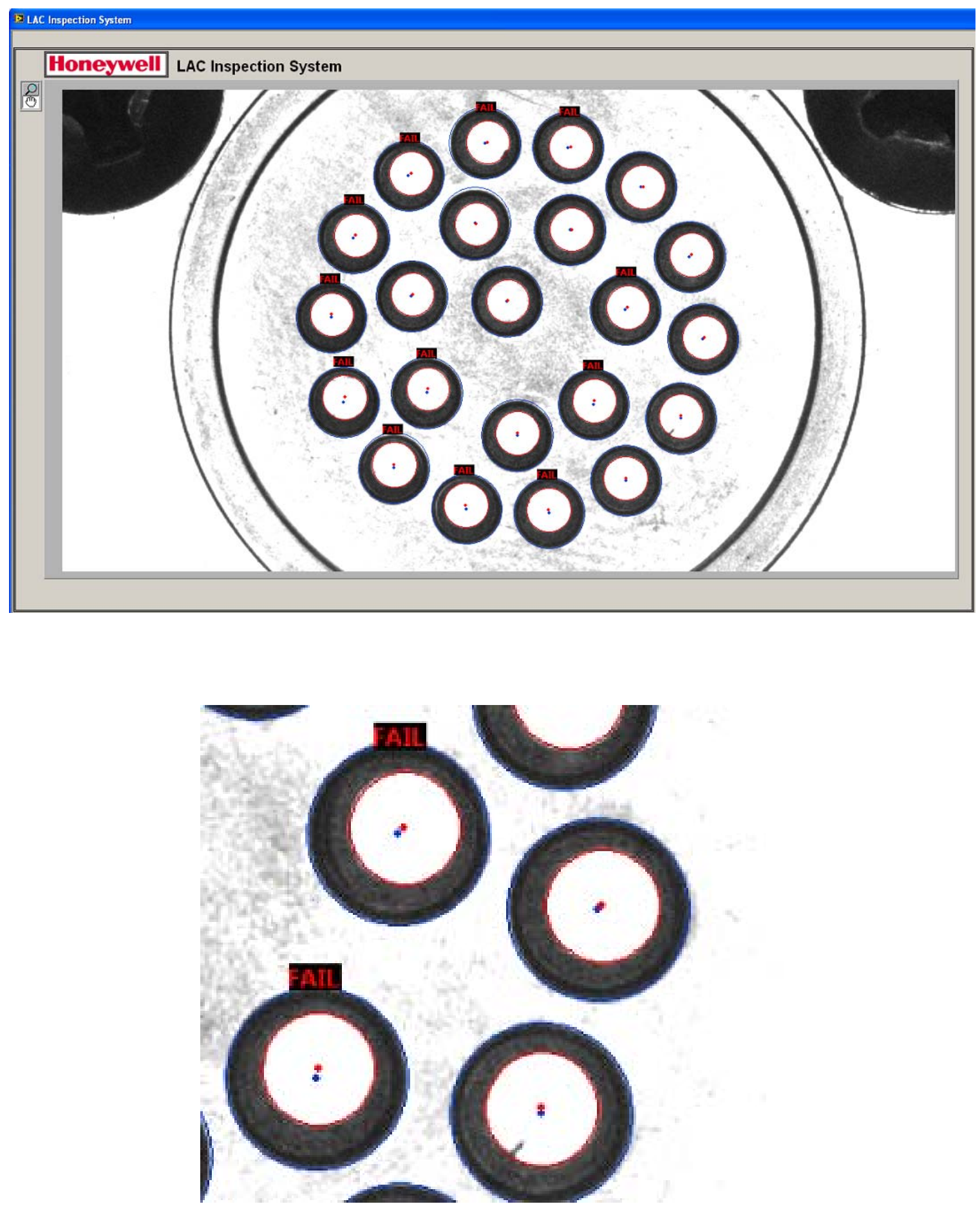

Figure 23.1: Web Disc detail 


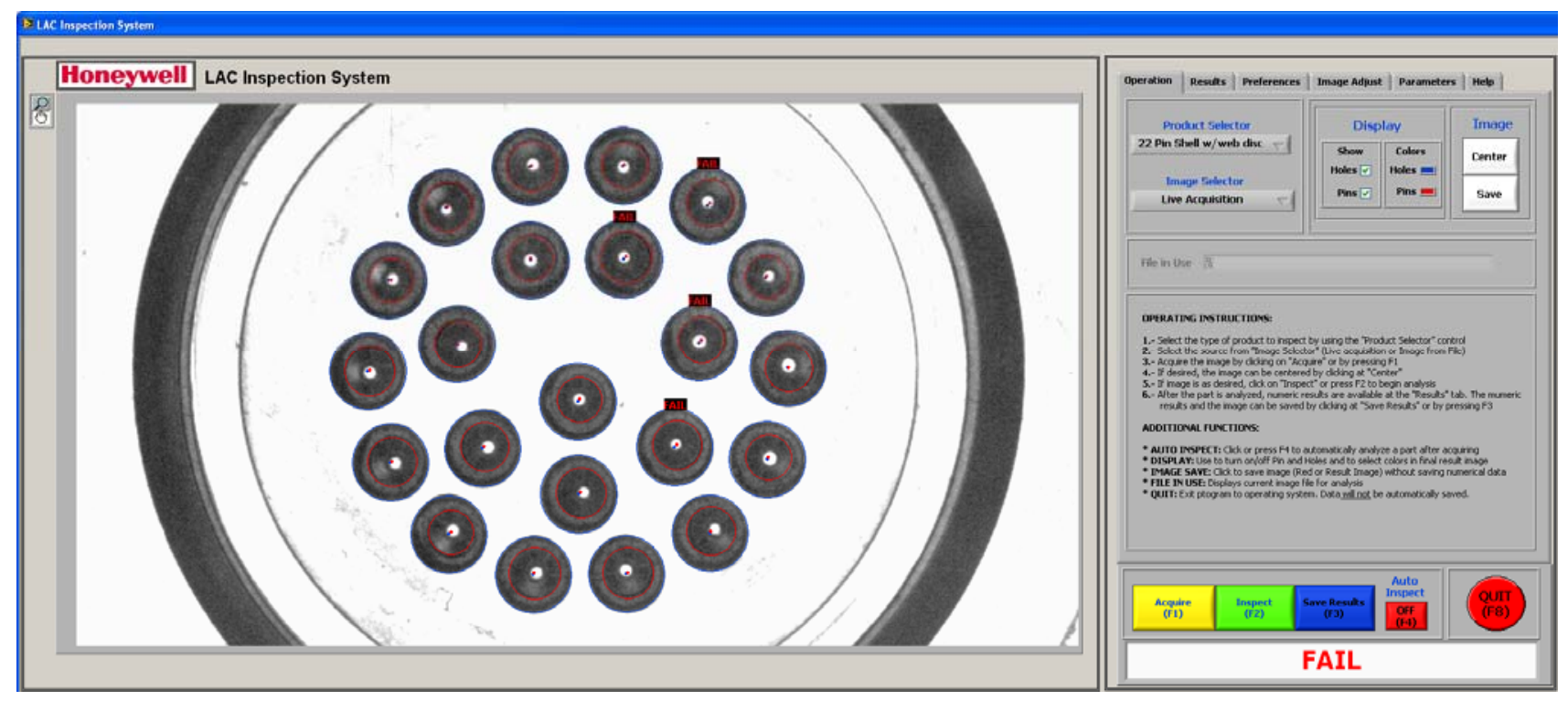

Figure 24: Shell assembly

\section{Conclusions}

The LAC Pin Placement Verification System has demonstrated its capabilities to provide unambiguous pass/fail test results by removing operator's subjectivity. This is an essential rule for reducing variability in production parts. It also has the flexibility of accepting new parts for verification as well as tolerance adjustment. Nevertheless, at this point the system lacks the robustness required for production use since its issues need to be resolved and more testing needs to be performed. A more definite pass/fail tolerance criterion also needs to be established. This work should not represent a great engineering effort, and this tool could be ready for production use in a reasonable amount of time. 


\section{Appendix \\ Second Vendor Cost Savings Calculations}

\begin{tabular}{|c|c|c|}
\hline & $\begin{array}{l}\text { Detailed } \\
\text { Costs }\end{array}$ & Sub Totals \\
\hline \multicolumn{3}{|l|}{ Cost of Arc Qualification } \\
\hline 50 parts @ $\$ 1,750$ per part & 104,125 & \\
\hline Setup charge & 81,813 & 185,938 Parts \\
\hline Source Inspect 100 hrs D612 @ \$65 & 7,735 & 7,735 Inspect \\
\hline \multicolumn{3}{|l|}{ Qualification Testing } \\
\hline D \$55 per hr (shock \& vib) & 15,054 & \\
\hline 2. 10 hours ? $\$ 45$ per hr (Cleaning \& vac bak) & 536 & \\
\hline$\supseteq \$ 47$ per hr (elec \& leak test) & 1,510 & \\
\hline 4. 100 hours L _.. $\gg \$ 75$ per hr (Project actifities) & 8,925 & 26,024 Qual Test \\
\hline \multicolumn{3}{|l|}{ QE Reviews } \\
\hline 1. Travel 2 people $\times 4$ trips $\times \$ 1500$ per trip & 14,280 & \\
\hline 2. Time 2 people $\times 4$ trips $\times 32$ hrs per trip & $\underline{22,848}$ & 37,128 QE Reviews \\
\hline Cost of Arc Qualification & $\$ 256,825$ & \\
\hline \multicolumn{3}{|l|}{ Program Cost of Parts From Arc } \\
\hline Supplier quote @ build qtys of 300 & 1,750 & \\
\hline Order Quantity of 290 per Year Yield (or 365 gross) & $\underline{365}$ & \\
\hline Cost of 365 parts & 638,750 & \\
\hline Setup charge per order (assumes 1 order per year) & $\underline{68,750}$ & \\
\hline Total Cost for 365 parts (also Estimated '1-Year' Order Qty) & $\$ 707,500$ & \\
\hline \multicolumn{3}{|l|}{ Estimated '1-Year' MMP Order Qty Cost } \\
\hline $\begin{array}{l}\text { Supplier quote @ build qtys of } 100 \text { (MMP would not quote more } \\
\text { than } 100 \text { quantity with full liability) }\end{array}$ & 3,199 & \\
\hline Order Quantity of 290 per Year Yield (or 365 gross => 4 orders) & $\underline{365}$ & \\
\hline Cost of 365 parts & $1,167, \overline{635}$ & \\
\hline Plus D-Test Lot Charge of $\$ 3,000$ per order & $\underline{12,000}$ & \\
\hline Total Cost of 365 parts & $\underline{\$ 1,179,635}$ & \\
\hline \multirow{2}{*}{\multicolumn{3}{|c|}{ '1-Year' Steady-State Production Cost Savings }} \\
\hline Arc '1-Year' Order Cost (3656 parts) & & \\
\hline \multicolumn{3}{|l|}{ Less Cost of '1-Year' Order Qty 365 parts from MMP @ \$3199 } \\
\hline ea. $+\$ 12,000$ D-Test Lot Charges & $1,179,635$ & \\
\hline '1-Year Steady-State Production Cost Savings & $\$ 472.135$ & \\
\hline \multicolumn{3}{|l|}{ '1-Year' Cost Savings Incl Arc Qualification } \\
\hline Cost to Qualify Arc & 256,825 & \\
\hline Plus Cost of 365 parts from Arc & $\underline{707,500}$ & \\
\hline Arc Cost & 964,325 & \\
\hline \multicolumn{3}{|l|}{ Less Cost of '1-Year' Order Qty 365 parts from MMP @ \$3199 } \\
\hline ea. + \$12,000 D-Test Lot Charges & $\underline{1,179,635}$ & \\
\hline '1-Year Cost Savings Incl Arc Qualification & $\$ 215,310$ & \\
\hline
\end{tabular}


Program Cost of Parts From Arc

Supplier quote @ build qtys of 300

1,750

Order Quantity of 290 per Year Yield (or 365 gross)

Cost of 365 parts

638,750

Setup charge per order (assumes 1 order per year)

68,750

Total Cost for 365 parts (also Estimated '1-Year' Order Qty)

707,500

Cost per Arc part $\$ 707500$ / 365 parts

1,939

Estimated quantity

2,818

Supplier quote @ MMP build qtys of 100

3,199

Estimated quantity

2,818

$9,014,782$

\# of D-Test Lots $=2818 / 100 \sim 29$

87,000

D-Test Lot Charges $=29$ D-Test Lots $\times \$ 3,000$ per Lot

$, 101,782$

Program Cost Savings

Cost to Qualify Arc

256,825

Plus Cost of parts from Arc

$\underline{5,464,102}$

Arc Program Cost

$5,720,927$

Program Cost of parts from MMP

$9,101,782$

Less Arc Program Cost

$\underline{-5,720,927}$

Beginning Program Cost Savings

$3,380,855$

Less extra cost for 1 year's parts while qualifying Arc

$-215,310$

Net Program Cost Savings

$\underline{\underline{3,165,545}}$ 